Article

\title{
Assessment of Multiple GNSS Real-Time SSR Products from Different Analysis Centers
}

\author{
Zhiyu Wang ${ }^{1,2}$, Zishen $\mathrm{Li}^{1, *}$, Liang Wang ${ }^{1,2, *}$, Xiaoming Wang ${ }^{1,3}$ (1) and Hong Yuan ${ }^{1}$ \\ 1 Academy of Opto-Electronics, Chinese Academy of Sciences, 9 Dengzhuang South Road, Haidian District, \\ Beijing 100094, China; wangzhiyu@aoe.ac.cn (Z.W.); wxm@aoe.ac.cn (X.W.); yuanh@aoe.ac.cn (H.Y.) \\ 2 University of Chinese Academy of Sciences, 19A Yuquan Road, Shijingshan District, Beijing 100049, China \\ 3 School of Environment and Spatial Informatics, China University of Mining and Technology, 1 Daxue Road, \\ Xuzhou 221116, China \\ * Correspondence: lizishen@aoe.ac.cn (Z.L.); wangliang115@mails.ucas.ac.cn (L.W.); \\ Tel.: +86-10-8217-8896 (Z.L. \& L.W.)
}

Received: 15 January 2018; Accepted: 7 March 2018; Published: 8 March 2018

\begin{abstract}
The real-time State Space Representation (SSR) product of the GNSS (Global Navigation Satellite System) orbit and clock is one of the most essential corrections for real-time precise point positioning (PPP). In this work, the performance of current SSR products from eight analysis centers were assessed by comparing it with the final product and the accuracy of real-time PPP. Numerical results showed that (1) the accuracies of the GPS SSR product were better than $8 \mathrm{~cm}$ for the satellite orbit and $0.3 \mathrm{~ns}$ for the satellite clock; (2) the accuracies of the GLONASS (GLObalnaya NAvigatsionnaya Sputnikovaya Sistema) SSR product were better than $10 \mathrm{~cm}$ for orbit RMS (Root Mean Square) and $0.6 \mathrm{~ns}$ for clock STD (Standard Deviation); and (3) the accuracies of the BDS (BeiDou Navigation Satellite System) and Galileo SSR products from CLK93 were about 14.54 and $4.42 \mathrm{~cm}$ for the orbit RMS and 0.32 and $0.18 \mathrm{~ns}$ for the clock STD, respectively. The simulated kinematic PPP results obtained using the SSR products from CLK93 and CLK51 performed better than those using other SSR products; and the accuracy of PPP based on all products was better than 6 and $10 \mathrm{~cm}$ in the horizontal and vertical directions, respectively. The real-time kinematic PPP experiment carried out in Beijing, Tianjin, and Shijiazhuang, China indicated that the SSR product CLK93 from Centre National d'Etudes Spatiales (CNES) had a better performance than CAS01. Moreover, the PPP with GPS + BDS dual systems had a higher accuracy than those with only a GPS single system.
\end{abstract}

Keywords: precise point positioning; orbits and clocks; state space representation; analysis centers

\section{Introduction}

Precise Point Positioning (PPP) is one of the most widely-used approaches for high-precision real-time positioning with the development of multi-frequency global navigation satellite systems (GNSS). However, the PPP approach relies heavily on the availability of the high-precision satellite orbit and clock corrections [1-9]. Currently, the International GNSS Service (IGS) agency and various analysis centers (ACs) provide users with precise satellite orbit and clock products through FTP (File Transfer Protocol) in three forms: ultra-rapid, rapid, and final [10-12]. The rapid and final orbit/clock products are available after around $17 \mathrm{~h}$ after the end of the previous UTC (Coordinated Universal Time) day and 13 days after the end of the solution week, respectively, which mean that they cannot be used for real-time applications [13]. Although ultra-rapid products are available for real-time applications, its accuracy is not good enough for high-precision PPP. Each ultra-rapid orbit file usually covers $48 \mathrm{~h}$, but only the first $24 \mathrm{~h}$ of the orbit are generated using actual observations and the second $24 \mathrm{~h}$ are extrapolated using the first 24 -h orbit. 
To meet the growing needs for real-time high-precision positioning and application, IGS founded a Real-Time Working Group in 2002 committed to the construction of infrastructure and to set up standards as well as technical specifications related to high-precision real-time GNSS [14]. In 2007, IGS started the Real-Time Pilot Project (RTPP) and has extended its capability to support applications requiring real-time access to IGS products since 2013 by providing GPS and GLONASS dual-system orbit and clock corrections based on RTCM (Radio Technical Commission for Maritime Services) and NTRIP (Networked Transport of RTCM via Internet Protocol) [15-21]. Multi-GNSS real-time orbit and clock products are also making headways with the development of BDS and Galileo. Currently, there are a wide collection of real-time orbit and clock products for either GPS or GPS + GLONASS, developed by ACs such as BKG (Bundesamt für Kartographie und Geodäsie), CNES (Centre National d'Etudes Spatiales), DLR (Deutsches Zentrum für Luft- und Raumfahrt), ESA (European Space Agency), GFZ (Deutsches GeoForschungsZentrum), and GMV (GMV Aerospace and Defense). CNES was the first to provide RTS for all four systems (GPS/GLONASS/BDS /GALILEO) since 2015 (IGS MAIL 7183).

Moreover, China started the construction of the international GNSS Monitoring and Assessment System (iGMAS) in 2012. The main task of iGMAS was to (1) establish a worldwide near-real-time tracking network for BDS, GPS, GLONASS, and Galileo; (2) build an information service platform for data collection, storage, analysis, management, and publication; (3) monitor and assess the operation status and key performance indicators of all GNSS [22]. At present, there are 30 global tracking stations, three data centers and eight analysis centers that can provide precise products to support satellite navigation technology testing, monitoring assessment, scientific research, and various applications [23].The Institute of Geodesy and Geophysics (IGG) of the Chinese Academy of Sciences (CAS), one of the iGMAS analysis centers, is also beginning to develop multi-system real-time orbit and clock correction products with the advance of iGMAS.

\section{The Acquisition of Real-Time Observation Data and State Space Representation Product}

It is critical for the real-time PPP to access real-time data and SSR products in an efficient way $[8,11,16,18,21,24]$. Accessing GNSS data via the Internet based on NTRIP has been widely used in many applications. For instance, it has been adopted in data transmission between CORS (Continuously Operating Reference Stations) servers and receivers. The NTRIP agreement, which officially became an RTCM standard in November 2004, is used for sending data streams in the format of RTCM 2.0 and 3.0. Real-time orbit and clock correction data generated by ACs in IGS-RTPP are released in SSR (State Space Representation) format in compliance with the RTCM standard and broadcasted via NTRIP (RTCM 2011). Figure 1 shows the broadcasting, receiving, and precise positioning process of real-time GNSS data/products. The GNSS data transmission system based on NTRIP generally consists of four parts: the data source, server (NtripServer), broadcaster (NtripCaster), and client terminal (NtripClient). The table of data sources generated by NTRIP broadcasters contains general information about data sources including their ID, RTCM version, data type, etc. One can access this table via the Internet on a client terminal, and select proper mount points to obtain raw data or corrections from NTRIP data sources with a short latency [25].

BKG Ntrip Client (BNC) is one of the most widely-used software package for obtaining real-time data and products [20], but it only supports data decoding in the RTCM format, making it difficult to broadcast real-time products in the latest format. In light of this, the GNSS research group at the IGG of Chinese Academy of Sciences has developed an alternative software named IGG-Ntrip, which presents the following features:

- Supports both RTCM and iGMAS formats;

- Supports real-time data and products for four systems (GPS/GLONASS/BDS/GALILEO) with multiple addresses and mount points;

- Provides a data sharing mechanism based on sharing memory and Socket;

- A user-friendly graphic interface that allows users to select stations on a map; 
All the real-time data and products used in this work were obtained via IGG-Ntrip.

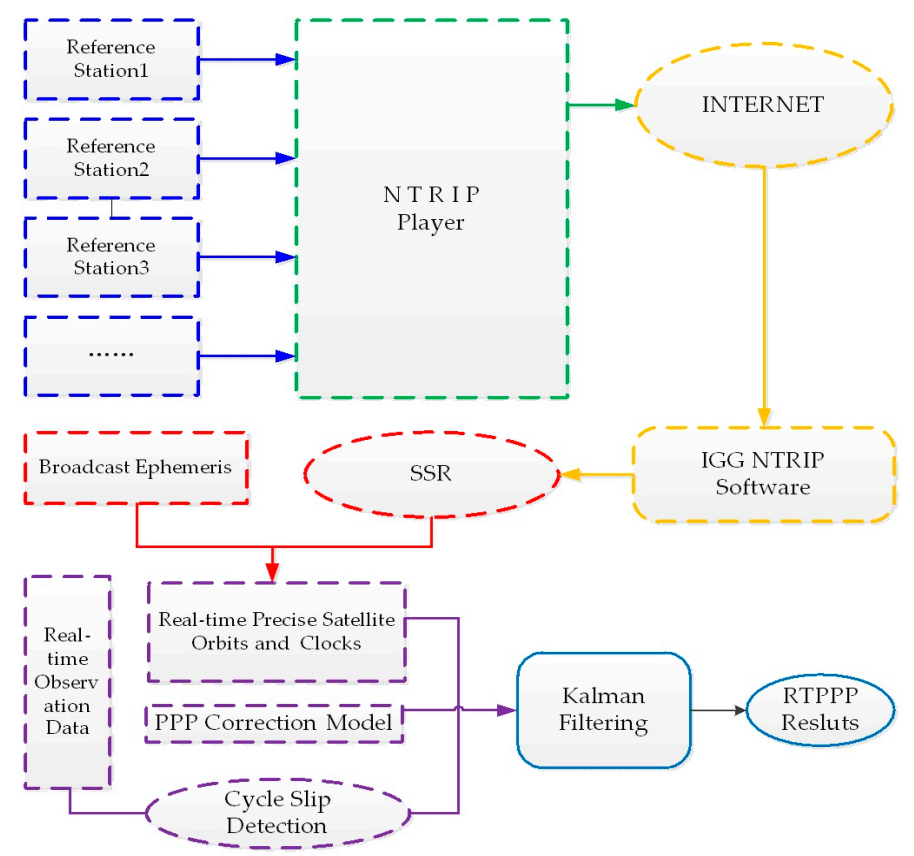

Figure 1. Broadcasting, receiving, and precise positioning process of real-time Global Navigation Satellite System (GNSS) data/products.

\section{Real-Time Precise Orbit and Clock Recovery}

The real-time data streams from IGS/ACs provide corrections of orbits and clocks to broadcast ephemeris. As above-mentioned, these corrections are essential for obtaining high-precision orbits and clocks for precise real-time PPP [10,26-28].

Real-time orbit corrections are provided in radial, along-track, and cross-track directions in a satellite-fixed coordinate system. Thus, it was necessary to first convert orbit corrections into an Earth-Fixed reference frame (ECEF) system, which was adopted for the positioning. RTCM-SSR corrections included the following parameters [29-31]:

$$
\Delta_{\mathrm{ssr}}\left(\mathrm{t}_{0}, \mathrm{IODE}\right)=\left(\delta \mathrm{O}_{\mathrm{r}}, \delta \mathrm{O}_{\mathrm{a}}, \delta \mathrm{O}_{\mathrm{c}}, \delta \mathrm{O}_{\mathrm{r}}^{\prime}, \delta \mathrm{O}_{\mathrm{a}}^{\prime}, \delta \mathrm{O}_{\mathrm{c}}^{\prime}, \mathrm{C}_{0}, \mathrm{C}_{1}, \mathrm{C}_{2}\right),
$$

where IODE is the issue of data; $\delta \mathrm{O}_{\mathrm{r}}, \delta \mathrm{O}_{\mathrm{a}}, \delta \mathrm{O}_{\mathrm{c}}, \delta \mathrm{O}_{\mathrm{r}}^{\prime}, \delta \mathrm{O}_{\mathrm{a}}^{\prime}, \delta \mathrm{O}_{\mathrm{c}}^{\prime}$ are the corrections and rate of change at time $t_{0}$ in the radial, along-track, and cross-track directions, respectively; $C_{0}, C_{1}, C_{2}$ are the polynomial coefficients for calculating clock corrections, respectively.

The orbit correction $\delta=\left[\begin{array}{lll}\delta_{\mathrm{r}} & \delta_{\mathrm{a}} & \delta_{\mathrm{c}}\end{array}\right]^{\mathrm{T}}$ at epoch $t$ can be calculated using Equation (2) based on the SSR product

$$
\delta=\left[\begin{array}{c}
\delta_{\mathrm{r}} \\
\delta_{\mathrm{a}} \\
\delta_{\mathrm{c}}
\end{array}\right]=\left[\begin{array}{c}
\delta \mathrm{O}_{\mathrm{r}} \\
\delta \mathrm{O}_{\mathrm{a}} \\
\delta \mathrm{O}_{\mathrm{c}}
\end{array}\right]+\left[\begin{array}{c}
\delta \mathrm{O}_{\mathrm{r}}^{\prime} \\
\delta \mathrm{O}_{\mathrm{a}}^{\prime} \\
\delta \mathrm{O}_{\mathrm{c}}^{\prime}
\end{array}\right]\left(\mathrm{t}-\mathrm{t}_{0}\right)
$$

After converting the corrections from the satellite-fixed system to the ECEF system in $\mathrm{X}, \mathrm{Y}$, and $\mathrm{Z}$ directions, the precise orbit $\mathrm{R}$ can be calculated using Equation (3),

$$
\mathrm{R}=\left[\begin{array}{c}
\mathrm{X} \\
\mathrm{Y} \\
\mathrm{Z}
\end{array}\right]=\left[\begin{array}{c}
\mathrm{x}_{\mathrm{b}} \\
\mathrm{y}_{\mathrm{b}} \\
\mathrm{z}_{\mathrm{b}}
\end{array}\right]-\left[\begin{array}{lll}
\overrightarrow{\mathrm{e}_{\mathrm{r}}} & \overrightarrow{\mathrm{e}_{\mathrm{a}}} & \overrightarrow{\mathrm{e}_{\mathrm{c}}}
\end{array}\right]\left[\begin{array}{c}
\delta_{\mathrm{r}} \\
\delta_{\mathrm{a}} \\
\delta_{\mathrm{c}}
\end{array}\right]
$$


where $\overrightarrow{\mathrm{e}_{\mathrm{r}}}, \overrightarrow{\mathrm{e}_{\mathrm{a}}}, \overrightarrow{\mathrm{e}_{\mathrm{c}}}$ are the unit vectors in the radial, along-track, and cross-track directions, respectively; $\mathrm{x}=\left[\begin{array}{lll}\mathrm{x}_{\mathrm{b}} & \mathrm{y}_{\mathrm{b}} & \mathrm{z}_{\mathrm{b}}\end{array}\right]^{\mathrm{T}}$ is the satellite orbit calculated from the broadcast ephemeris.

It should be noted that there are two types of reference points for satellite position corrections in the SSR messages provided by NTRIP: APC (antenna phase center) and COM (center of mass). The data source table provided by the NTRIP casters indicates which reference point is used. If APC is adopted, the antenna phase bias correction shall be taken into account to obtain the coordinates of the satellite's center of mass under ITRF.

Regarding the recovery of precise clocks, Equation (4) is used to determine the clock correction $\Delta \mathrm{k}$ at epoch $\mathrm{t}$ with the polynomial coefficients $\mathrm{C}_{0}, \mathrm{C}_{1}, \mathrm{C}_{2}$ given at the reference epoch $\mathrm{t}_{0}$.

$$
\Delta \mathrm{k}=\mathrm{C}_{0}+\mathrm{C}_{1}\left(\mathrm{t}-\mathrm{t}_{0}\right)+\mathrm{C}_{2}\left(\mathrm{t}-\mathrm{t}_{0}\right)^{2}
$$

Then, the precise satellite clock $\Delta \mathrm{t}_{\mathrm{s}}$ at epoch $\mathrm{t}$ can be calculated with the following equation,

$$
\Delta \mathrm{t}_{\mathrm{s}}=\Delta \mathrm{t}_{\mathrm{b}}-\frac{\Delta \mathrm{k}}{\mathrm{V}_{\mathrm{c}}}
$$

where $V_{c}$ is the speed of light in the vacuum; and $\Delta t_{b}$ is the clock correction generated from the broadcast ephemeris.

\section{Assessment of the Real-Time Orbit and Clock Corrections for Multi-GNSS}

The precision of orbit and clock corrections is a critical issue for high-precision positioning using PPP. In this study, the satellite orbits and clocks were calculated epoch-by-epoch using the above-mentioned method with the multi-GNSS SSR products provided by eight selected ACs. The results were then compared against the final precise products released by IGS/ACs to assess the accuracy of these multi-system real-time orbit and clock corrections.

The real-time products used in this study were developed by IGS, BKG, DLR, ESA, GFZ, GMV, CNES, and CAS, as listed in Table 1 in detail. It can be seen from Table 1 that all products supported GPS, while the products CLK93 and CAS01 supported BDS and Galileo. The data used in this experiment were collected from 12 to 18 September 2017 with a sampling interval of $30 \mathrm{~s}$. The final products released by IGS and ESA were selected as references for assessing the performance of real-time SSR products for GPS and GLONASS systems, respectively, while for BDS and Galileo, the final products of GBM (Geodetic Benchmark) released by GFZ were used as references.

Table 1. The details of the real-time products used in this work.

\begin{tabular}{ccccccccc}
\hline ACs & IGS & BKG & DLR & ESA & GFZ & GMV & CNES & CAS \\
\hline Products & IGS03 & CLK10 & CLK20 & CLK51 & CLK70 & CLK80 & CLK93 & CAS01 \\
System & G + R & G & G + R & G & G + R & G + R & G + R + C + E & G + R + C + E \\
\hline
\end{tabular}

The RMS of differences between orbits calculated using real-time corrections and final products was calculated for the radial (R), along-track (A), and cross-track (C) directions in a satellite-fixed coordinate system with the equation

$$
\mathrm{RMS}=\sqrt{\sum_{\mathrm{i}=1}^{\mathrm{n}} \frac{\Delta_{\mathrm{i}}^{2}}{\mathrm{n}}}
$$

where $\Delta_{\mathrm{i}}$ represents the orbit mutual differences in nodes; and $\mathrm{n}$ is the number of mutual differences.

For clock comparison, the RMS and STD of the differences between the real-time clock and the reference clock are generally calculated for the assessment after unifying statistical criteria, where RMS reflects the compliance of clock correction and pseudo-range, while STD represents the real resolution precision of clock correction which has a great influence on processing phase data [21,32]. Meanwhile, we considered the mean of the clocks for all the satellites as zero as the datum instead of selecting a 
reference satellite as the datum $[3,28]$, which may cause the loss of precision for the reference satellite. The adopted mathematical approach is as follows:

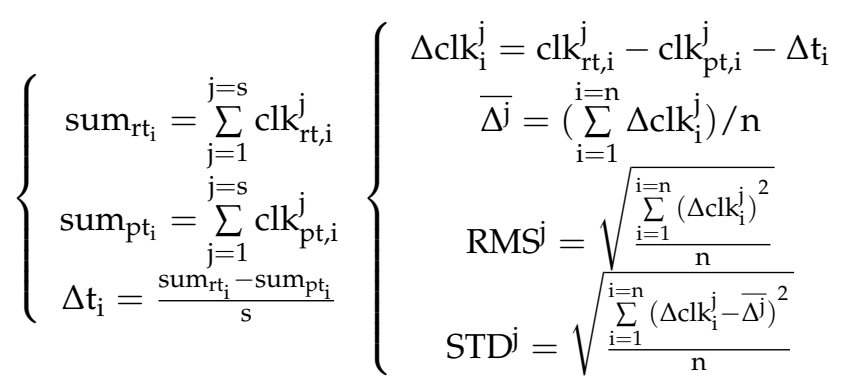

where $i$ and $j$ are the epoch and the satellite number; $n$ is the sum of epochs; $\mathrm{s}$ is the number of satellites; $\mathrm{clk}_{\mathrm{rt}, \mathrm{i}}^{\mathrm{j}}$ and $\mathrm{clk}_{\mathrm{pt}, \mathrm{i}}^{\mathrm{j}}$ are the real-time and post-processing reference clock corrections; $\Delta \mathrm{t}_{\mathrm{i}}$ is the datum difference between the two clock correction products with the selected datum; RMS ${ }^{j}$ and STD $^{j}$ are the statistical indicators of RMS and STD, respectively.

\subsection{Validation Results of GPS Real-Time Orbit and Clock Products}

Using the IGS final product as the reference, the RMS of the differences of the GPS real-time orbit products from the eight selected ACs are shown in Figure 2, where the RMS of the orbit differences were calculated in the R, A, and C directions, respectively, as denoted by the red, green, and blue bars; the RMS and STD of the differences of the GPS real-time clock products from the eight selected ACs are shown by the blue and red bars in Figure 3. The average accuracies of the orbit and clock corrections for each product over all the GPS satellites are given in Table 2.
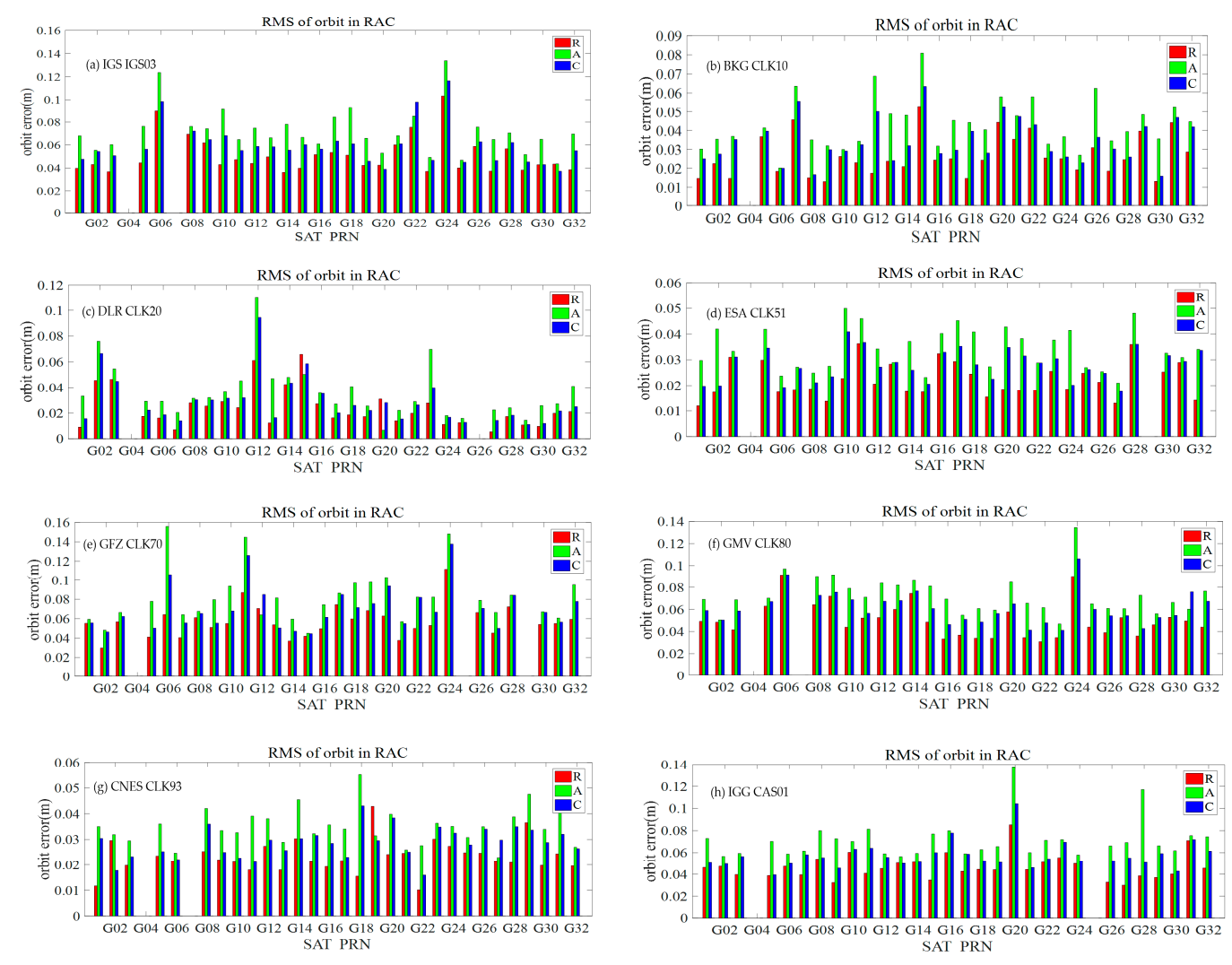

Figure 2. The RMS of the differences of real-time GPS orbit between the eight selected ACs' products and the IGS final product. 

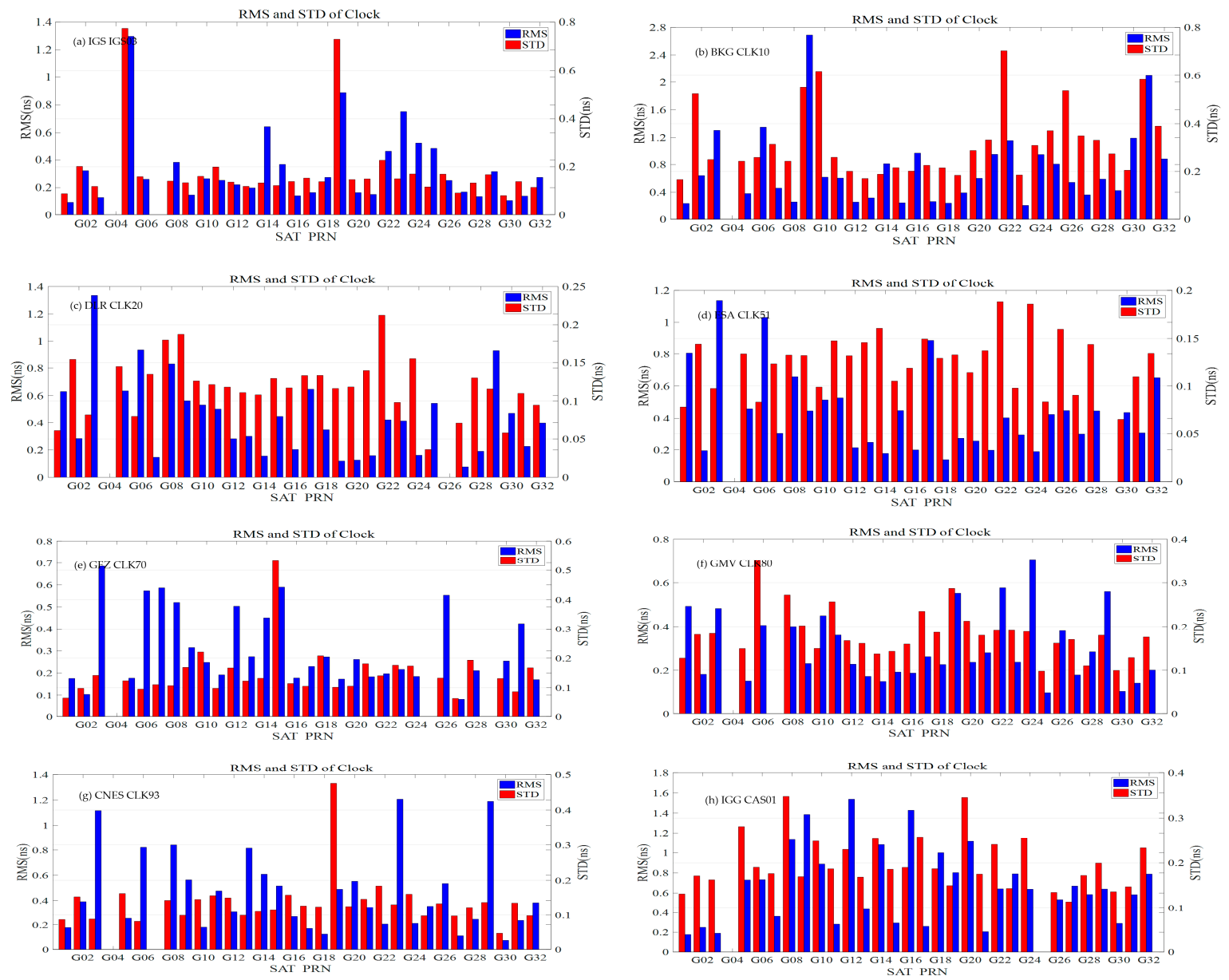

Figure 3. The Root Mean Square (RMS) (blue bar) and Standard Deviation (STD) (red bar) of the differences of real-time Global Positioning System (GPS) clock between the eight selected analysis centers' (ACs') products and the International GNSS Service (IGS) final product.

Table 2. The average accuracies of GPS real-time orbit and clock products from the eight selected ACs with respect to the IGS final products during the test period.

\begin{tabular}{ccccccc}
\hline \multirow{2}{*}{ Products } & \multicolumn{9}{c}{ Orbits (cm) } & \multicolumn{2}{c}{ Clocks (ns) } \\
\cline { 2 - 7 } & $\mathbf{R}$ & $\mathbf{A}$ & $\mathbf{C}$ & 1DRMS & RMS & STD \\
\hline IGS03 & 5.79 & 8.04 & 7.02 & 7.01 & 0.35 & 0.19 \\
CLK10 & 2.76 & 4.17 & 3.56 & 3.54 & 0.79 & 0.29 \\
CLK20 & 2.48 & 3.97 & 2.94 & 3.19 & 0.43 & 0.12 \\
CLK51 & 2.09 & 3.29 & 2.74 & 2.75 & 0.46 & 0.13 \\
CLK70 & 5.14 & 7.46 & 6.11 & 6.31 & 0.32 & 0.18 \\
CLK80 & 5.05 & 7.19 & 5.95 & 6.13 & 0.31 & 0.17 \\
CLK93 & 2.19 & 3.50 & 2.79 & 2.88 & 0.45 & 0.14 \\
CAS01 & 5.01 & 6.77 & 5.67 & 5.86 & 0.69 & 0.19 \\
\hline
\end{tabular}

It can be seen from Table 2 that the accuracies of the GPS orbit product in the radial direction was much better than that in the along-track and cross-track directions. The CLK51 performed the best in the 1D-RMS comparison, i.e., 2.09, 3.29, and $2.74 \mathrm{~cm}$ in the radial, along-track, and along-cross directions, respectively, while the IGS03 was the worst, i.e., $5.79,8.04$, and $7.02 \mathrm{~cm}$, again in those three directions. Regarding the GPS real-time clock product, all the RMS and STD were better than 0.5 and $0.2 \mathrm{ns,}$ except for CLK10 and CAS01. The real-time GPS clock product from CLK80 was the best with an RMS of $0.31 \mathrm{~ns}$ and STD of $0.17 \mathrm{~ns}$, while the CLK10 was the worst one with an RMS of 0.79 ns and STD 
of 0.29 ns. Overall, the real-time GPS orbit and clock product from CLK51 and CLK93 basically had the same accuracy, i.e., the 1D-RMS of the orbit product was better than $3.0 \mathrm{~cm}$ and the STD of the clock product was better than $0.15 \mathrm{~ns}$. The differences in accuracies between the different ACs may have resulted because of the different distributions of contributed stations and the different strategies adopted by CLK51 and CLK93; however, these differences generally do not affect the real-time PPP achieving a positioning with about a $5-10 \mathrm{~cm}$ accuracy. Aside from the accuracy of the products from different ACs, it should be noted that the latency of the real-time SSR corrections is also an important aspect that should be taken into account in the quality assessment since the positioning accuracy will decrease with the increasing latency of the real-time SSR corrections [33]. It can be seen from Table 3, that the CLKxx products generally had a latency of about 4-10 s, but the latency for the IGS03 products was around $30 \mathrm{~s}$. Meanwhile, we also analyzed different generations of GPS satellites (BLOCKIIR-A, BLOKII-B, BLOKIIR-M, BLOKIIF) using the same product, but we did not find anything particularly regular. Thus, we were able to conclude that the accuracy of orbits and clock products had no obvious correlation with different satellite generations.

Table 3. The latency of the real-time State Space Representation (SSR) corrections from different ACs.

\begin{tabular}{ccc}
\hline Products & Orbit/Clock Update Interval & Latency of Orbit/Clock \\
\hline CLK10 & $60 \mathrm{~s} / 5 \mathrm{~s}$ & $5 \mathrm{~s}$ \\
CLK20 & $5 \mathrm{~s} / 5 \mathrm{~s}$ & $4 \mathrm{~s}$ \\
CLK51 & $5 \mathrm{~s} / 5 \mathrm{~s}$ & $6 \mathrm{~s}$ \\
CLK70 & $10 \mathrm{~s} / 5 \mathrm{~s}$ & $6 \mathrm{~s}$ \\
CLK80 & $5 \mathrm{~s} / 5 \mathrm{~s}$ & $6 \mathrm{~s}$ \\
CLK93 & $5 \mathrm{~s} / 5 \mathrm{~s}$ & $8 \mathrm{~s}$ \\
CAS01 & $1 \mathrm{~s} / 1 \mathrm{~s}$ & $8 \mathrm{~s}$ \\
IGS03 & $60 \mathrm{~s} / 10 \mathrm{~s}$ & $28 \mathrm{~s}$ \\
\hline
\end{tabular}

\subsection{Validation Results of GLONASS Real-Time Orbit and Clock Products}

Different from the real-time GPS orbit and clock products, the GLONASS products are only broadcasted in IGS03, CLK20, CLK70, CLK80, CLK93, and CAS01. The performance of GLONASS products is validated by comparing them with the ESA final product. The accuracies of GLONASS orbits are also given in the radial, along-track, and along-cross directions shown in Figure 4, and the accuracies of the GLONASS clock products from the selected ACs are given in Figure 5. The average accuracies of the GLONASS satellite orbit and clock products during the test period are illustrated in Table 4. It should be noted that the satellite orbits of R12 and R14 were absent in the products from IGS03, CLK70, CLK 80, CLK93, and CAS01 in the test period, and the result of R8 and R12 were also absent in the products from CLK20 and CLK80, respectively.

Table 4. The average accuracies of GLObalnaya NAvigatsionnaya Sputnikovaya Sistema (GLONASS) orbit and clock products from the six selected ACs compared with the IGS final products during the test period.

\begin{tabular}{ccccccc}
\hline \multirow{2}{*}{ Products } & \multicolumn{3}{c}{ Orbits (cm) } & \multicolumn{2}{c}{ Clocks (ns) } \\
\cline { 2 - 7 } & R & A & C & 1DRMS & RMS & STD \\
\hline IGS03 & 5.34 & 8.74 & 6.95 & 7.15 & 9.38 & 0.50 \\
CLK20 & 4.45 & 7.09 & 5.69 & 5.84 & 8.29 & 0.31 \\
CLK70 & 6.21 & 8.55 & 7.73 & 7.56 & 1.74 & 0.17 \\
CLK80 & 6.44 & 9.02 & 7.46 & 7.71 & 0.82 & 0.33 \\
CLK93 & 4.15 & 7.16 & 5.32 & 5.68 & 2.97 & 0.21 \\
CAS01 & 10.33 & 34.84 & 20.57 & 24.11 & 5.49 & 1.86 \\
\hline
\end{tabular}



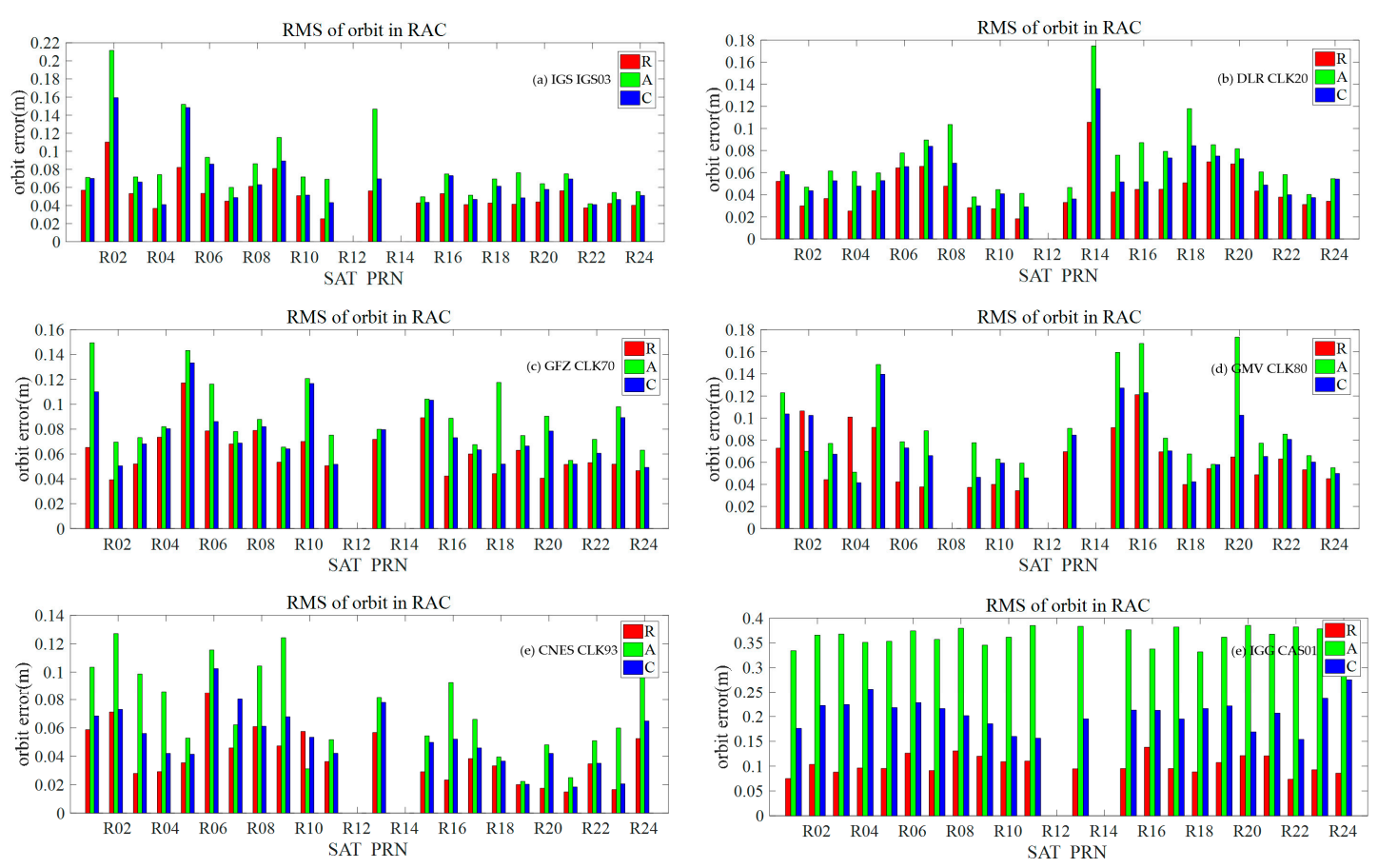

Figure 4. The RMS of the differences of real-time GLONASS orbit between the six selected ACs' products and the European Space Agency (ESA) final product.
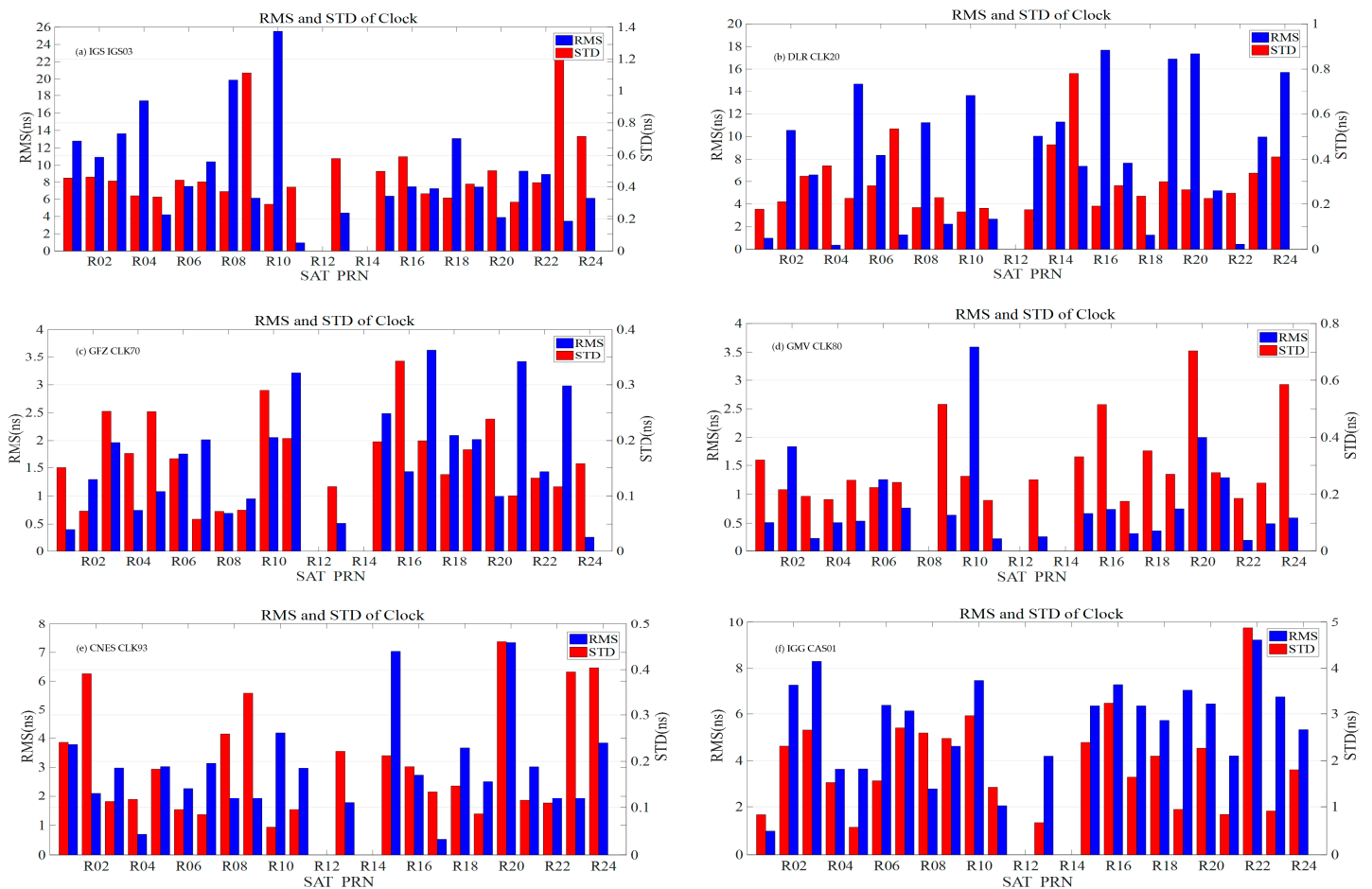

Figure 5. The RMS (blue bar) and STD (red bar) of the differences of real-time GLONASS clock between the six selected ACs' products and the IGS final product.

It can be seen from Table 4 that the average accuracy (1D-RMS) of the real-time GLONASS satellite orbit from all the ACs was almost at the same level (about 5-8 cm) except for the product from CAS01. Except for IGS03 and CAS01, the STDs of the real-time GLONASS satellite clock products from the other ACs were about $0.2-0.3 \mathrm{~ns}$. Regarding the RMS of the GLONASS satellite clock, although the different 
references in the clock products from different ACs was considered before comparison, all the products performed much worse than that of the GPS satellite except for the products from CLK93, leaving large room for improvement. In particular, the RMS of IGS03 was $9.38 \mathrm{~ns}$, and even higher for R10 (26 ns). The reason may be that GLONASS adopts FDMA and different ACs adopt different strategies in dealing with pseudo-range IFB in resolving clock corrections [34,35]. In addition, the GLONASS product from CAS01 is calculated by the Institute of Geodesy and Geophysics and broadcasted by the Academy of Opto-Electronics. However, it is currently in the initial and test phase and the performance of the GLONASS product will be further improved. At the same time, the different generations of GLONASS satellite (GLONASS-M and GLONASS-KI) were analyzed by the same product, and we also found nothing regular between them.

\subsection{Validation Results of BDS and Galileo Real-Time Orbit and Clock Products}

The real-time BDS and Galileo orbit and clock products are currently only broadcast by CLK93. The real-time BDS and Galileo products were validated by comparing them with the final precise product "GBM" released by GFZ. The validation results of the BDS/Galileo orbit and clock product are shown in Figures 6 and 7, respectively; and their average accuracy during the test period is illustrated in Table 5. In the test period, the BDS constellation consisted of five GEO, six IGSO- and three MEO-satellites, and the accuracies of the real-time or final orbit and clock product for those GEO satellites were generally much worse than those of other satellites due to the poor geometry of the GEO satellites tracked by the ground stations in orbit and clock determination. Thus, the results for the BDS IGSO (C06-C10, C13) and MEO (C11, C12, C14) satellites were only considered in our experiment. In view of the Galileo constellation, there are 17 satellites in orbit, of which 15 satellites are marked as available in the ephemeris, and CLK93 estimates the orbit and clock only for those available satellites.

Table 5. The average accuracies of the BeiDou Navigation Satellite System (BDS)/Galileo orbit and clock products from CLK93 when compared with the GBM final product during the test period.

\begin{tabular}{ccccccc}
\hline \multirow{2}{*}{ System } & \multicolumn{3}{c}{ Orbits (cm) } & \multicolumn{2}{c}{ Clocks (ns) } \\
\cline { 2 - 7 } & $\mathbf{R}$ & A & C & 1DRMS & RMS & STD \\
\hline BDS & 7.83 & 14.75 & 18.85 & 14.54 & 3.00 & 0.32 \\
Galileo & 3.21 & 5.39 & 4.41 & 4.42 & 0.39 & 0.18 \\
\hline
\end{tabular}
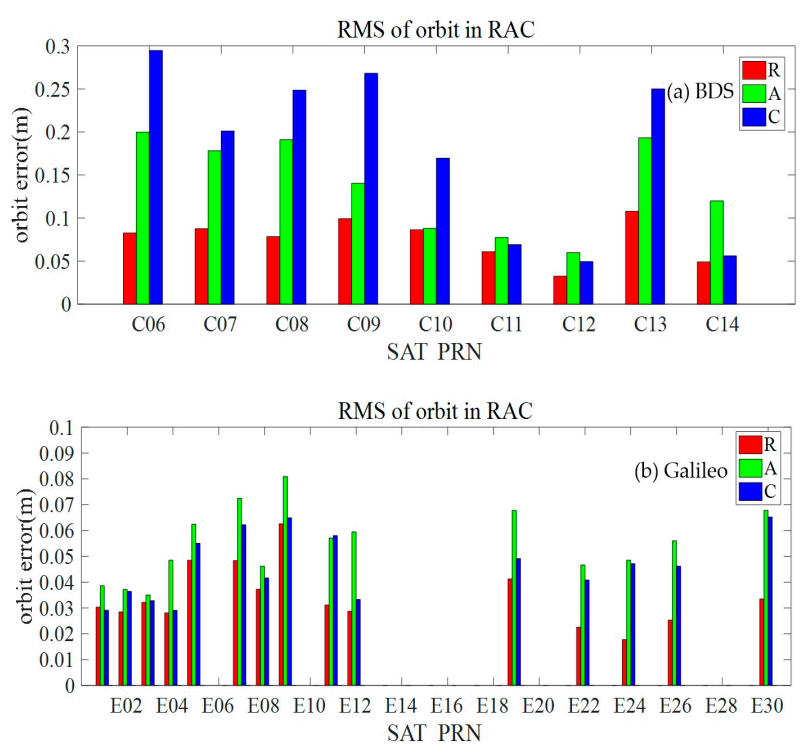

Figure 6. The RMS of the differences of the BDS and Galileo orbit between the CLK93 real-time product and the GBM final product. 

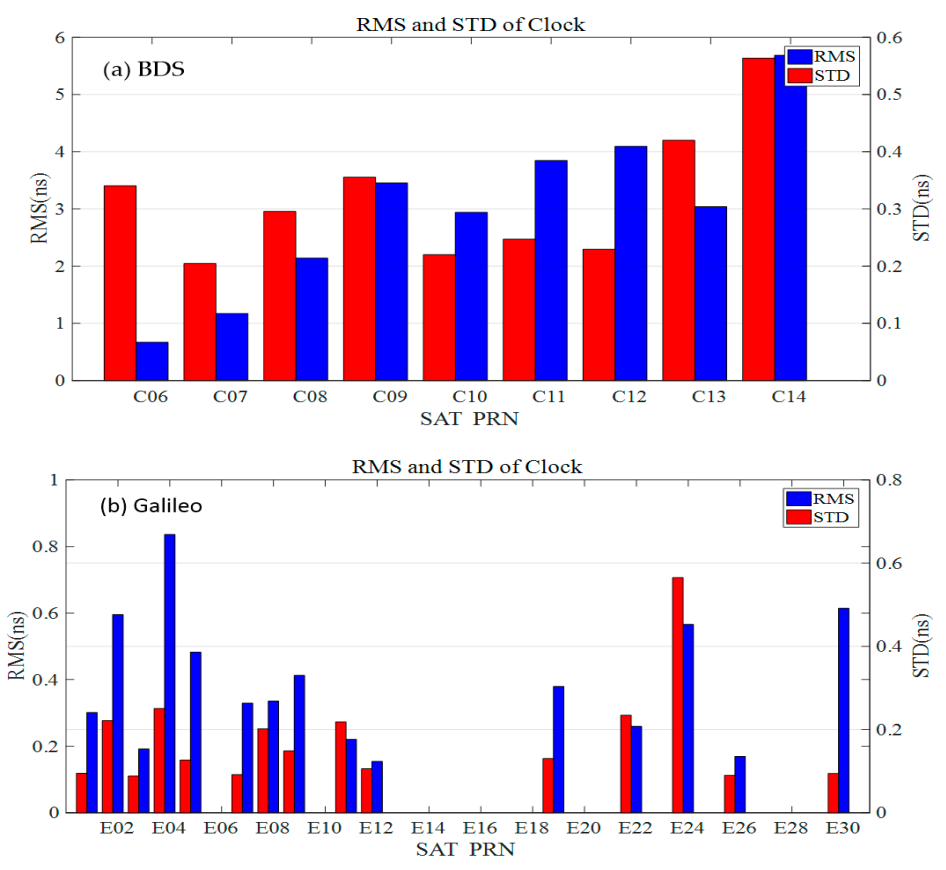

Figure 7. The RMS (blue bar) and STD (red bar) of the differences of BDS (top) and Galileo (bottom) between the CLK 93 real-time product and the GBM final product.

It can be seen from Figure 6 that the real-time Galileo orbit was more accurate than that of BDS, but a bit worse than that of GPS, and the accuracy of the BDS MEO satellites was better than that of the BDS IGSO satellites. Regarding the real-time clock accuracy shown in Figure 7, the Galileo satellites also outperformed the BDS satellites. It can be found in Table 5 that the differences of BDS satellite orbits between the CLK93 real-time product and the GBM final product in the radial, along-track, and along-cross directions were individually $7.83,14.75$, and $18.85 \mathrm{~cm}$. The average STD of real-time BDS satellite clock product was $0.32 \mathrm{~ns}$, and its average RMS reached $3.00 \mathrm{~ns}$ where the RMS of MEO satellites was larger than that of the IGSO satellites. Moreover, the differences of the Galileo satellite orbits between the real-time CLK93 product and the GBM final product in the radial, along-track, and along-cross directions were $3.21,5.39$, and $4.41 \mathrm{~cm}$, respectively. The average STD of clock correction was $0.18 \mathrm{~ns}$, while the average RMS was $0.39 \mathrm{~ns}$. All in all, the performance of the Galileo satellite orbits and clocks was much better than that of BDS in the CLK93 product. The primary reason is that the number of contributed ground stations that can track BDS satellites is much smaller than that of Galileo.

\section{Positioning Results of Real-Time PPP with IGS Stations}

The GNSS satellite orbit and clock products are generally used for the real-time precise point positioning. In this section, we further validated the performance of real-time products by the PPP technique. The PPP software used in this experiment, named RTPosNavi_AOE (version 1.0.17a, Beijing, China), was developed by the Academy of Opto-Electronics (AOE) based on the open-source software RTKLIB (version 2.4.3, Japan) [19]. The PPP rover used for this validation was conducted in static and kinematic modes, respectively, but the data processing strategy was all designed as kinematic mode, i.e., the estimated parameters of rover coordinates in two neighboring epochs were considered as independent. The PPP observation model was the ionosphere-free (IF) combination of dual-frequency carrier phase and pseudo-range observations, and the Kalman filter was adopted for parameter estimation. The specific processing strategy is listed in Table 6 . To evaluate the accuracy of real-time PPP, the real-time data stream in RTCM format from 10 stations from the IGS/MGEX 
network was selected in this study. The distribution of the selected stations for the experiment is shown in Figure 8.

Table 6. The processing strategy for precise point positioning (PPP) used for validating the performance of the real-time GNSS orbit and clock product.

\begin{tabular}{ccc}
\hline Index & Items & Processing Strategies \\
\hline 1. & Rover coordinates & Real-time estimation; initial value determined by SPP \\
2. & Ionospheric delay & Ionosphere-free combination \\
3. & Satellite orbit and clock & SSR corrections + Broadcast Ephemeris \\
4. & Receiver clock & Real-time estimation \\
5. & Tropospheric delay & Saastamoinen model + real-time estimation \\
6. & Antenna PCO/PCV & igs14.atx \\
7. & Cut-off elevation angle & $7^{\circ}$ \\
8. & Ambiguity & Float \\
9. & Cycle Slip & Detected by MW and GF \\
\hline
\end{tabular}

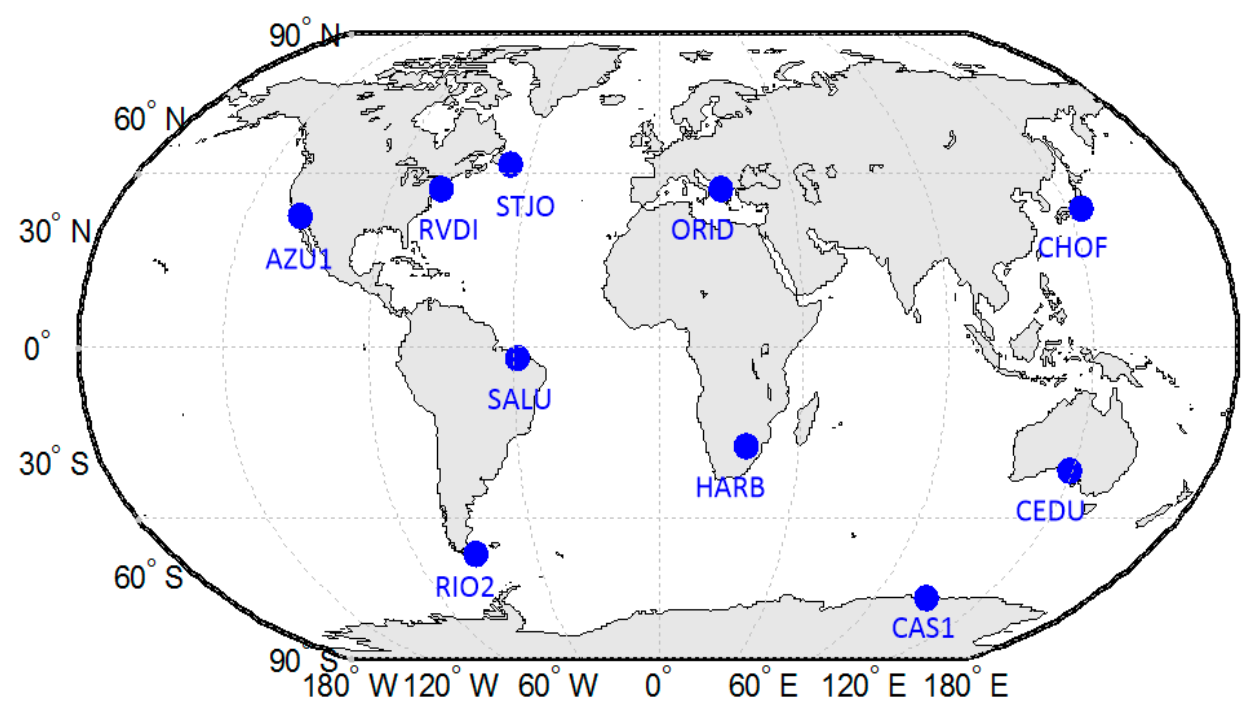

Figure 8. The distribution of the selected stations for the real-time PPP test experiment.

\subsection{Result of Real-Time PPP in Static Mode}

In this section, the selected reference stations were tested for static mode. RTPosNavi_AOE received the real-time raw data and the GNSS satellite orbit and clock products via IGG-Ntrip software carried out the PPP result. Taking the case of the CEDU station as an example, our experiment began at 00:00:00 (UTC) on 16 February 2018 and lasted for $20 \mathrm{~h}$. The time series of the differences between the PPP-estimated and IGS-released coordinates in the E (East-West), N (North-South), and U (Up-Down) directions are shown in Figure 9, where the convergence time was usually less than $30 \mathrm{~min}$, and the positioning accuracy after finishing the convergence process was almost better than $10 \mathrm{~cm}$ in the $\mathrm{E}, \mathrm{N}$, and $\mathrm{U}$ directions.

Table 7 shows the average positioning accuracies of the static mode in the $\mathrm{E}, \mathrm{N}$, and $\mathrm{U}$ directions during all test periods (without the convergence time) for all selected stations. Regarding 3D positioning accuracy, CLK93 had the best performance (about $4.18 \mathrm{~cm}$ ), followed by CLK51, IGS03, CAS01, CLK70, CLK80, CLK10, and CLK20. Thus, we concluded that the real-time PPP could achieve a positioning with an accuracy of about $6 \mathrm{~cm}$, provided one was able to obtain the real-time orbit and clock products from the current eight selected ACs. 

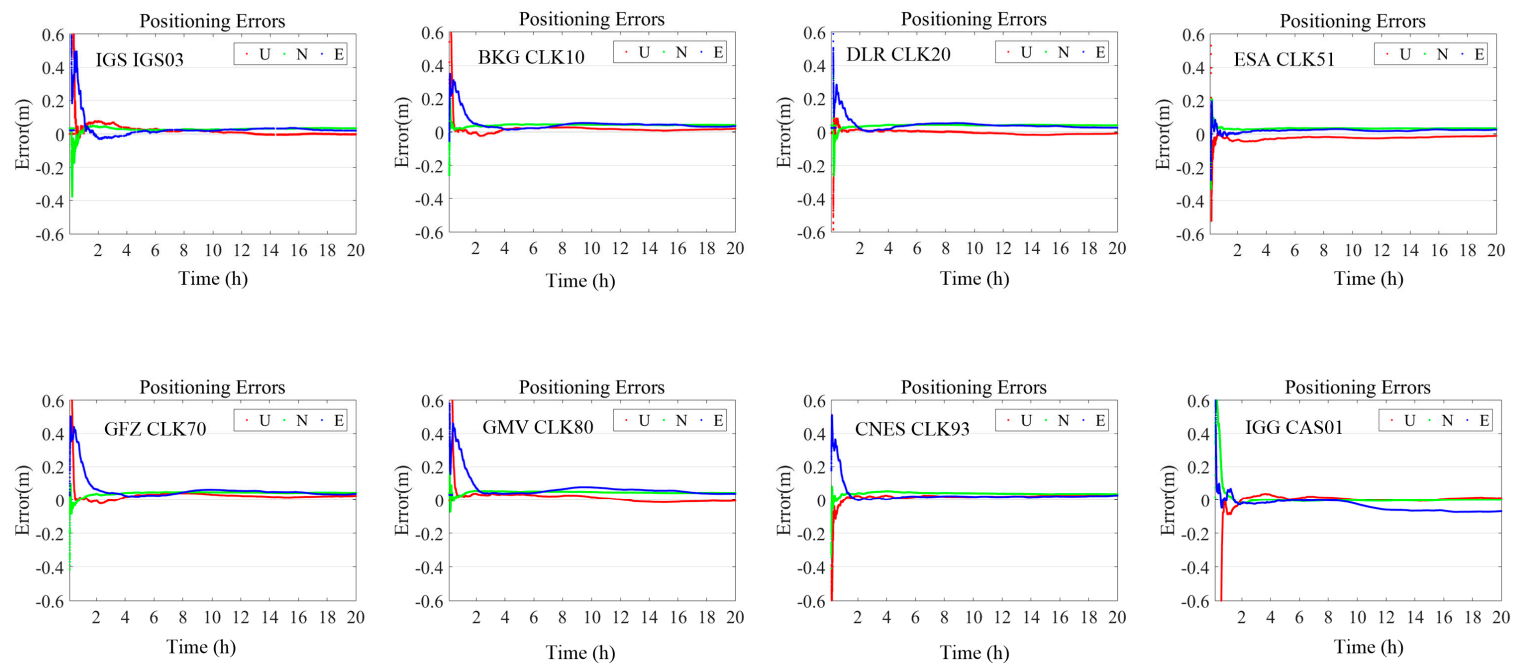

Figure 9. Time series of the differences between PPP-estimated (static mode) and IGS-released coordinates in E (East-West), N (North-South), U (Up-Down) directions at CEDU station. The results based on the real-time products from IGS03, CLK10, CLK20, CLK51, CLK70, CLK80, CLK93, and CAS01 are individually illustrated by each sub-figure.

Table 7. Static mode positioning RMS of the PPP-estimated result using the orbit and clock products from different ACs.

\begin{tabular}{|c|c|c|c|c|c|c|c|c|c|}
\hline Stations & Direction $(\mathrm{cm})$ & $\begin{array}{c}\text { IGS } \\
\text { IGS03 }\end{array}$ & $\begin{array}{l}\text { BKG } \\
\text { CLK10 }\end{array}$ & $\begin{array}{c}\text { DLR } \\
\text { CLK20 }\end{array}$ & $\begin{array}{c}\text { ESA } \\
\text { CLK51 }\end{array}$ & $\begin{array}{c}\text { GFZ } \\
\text { CLK70 }\end{array}$ & $\begin{array}{l}\text { GMV } \\
\text { CLK80 }\end{array}$ & $\begin{array}{l}\text { CNES } \\
\text { CLK93 }\end{array}$ & $\begin{array}{c}\text { CAS } \\
\text { CAS01 }\end{array}$ \\
\hline \multirow{4}{*}{ CEDU } & E & 1.94 & 3.75 & 3.09 & 2.63 & 3.16 & 2.91 & 2.04 & 3.82 \\
\hline & $\mathrm{N}$ & 3.62 & 3.61 & 4.75 & 3.13 & 4.22 & 2.98 & 2.81 & 0.12 \\
\hline & $\mathrm{U}$ & 2.91 & 2.81 & 2.57 & 2.15 & 0.33 & 3.14 & 1.20 & 1.69 \\
\hline & $3 \mathrm{D}$ & 5.04 & 5.91 & 6.22 & 4.62 & 5.28 & 5.21 & 3.67 & 4.17 \\
\hline \multirow{4}{*}{ AZU1 } & E & 2.01 & 3.82 & 3.15 & 3.61 & 3.02 & 3.19 & 2.11 & 2.66 \\
\hline & $\mathrm{N}$ & 3.64 & 3.65 & 4.78 & 0.99 & 3.02 & 4.21 & 2.85 & 3.16 \\
\hline & $\mathrm{U}$ & 2.88 & 2.79 & 2.62 & 2.65 & 3.11 & 0.38 & 1.18 & 2.17 \\
\hline & $3 \mathrm{D}$ & 5.06 & 5.97 & 6.30 & 4.59 & 5.28 & 5.30 & 3.74 & 4.67 \\
\hline \multirow{4}{*}{ RVDI } & $\mathrm{E}$ & 1.95 & 3.8 & 3.16 & 3.58 & 3.17 & 3.11 & 2.15 & 2.56 \\
\hline & $\mathrm{N}$ & 3.59 & 3.71 & 4.72 & 1.14 & 3.36 & 3.11 & 2.95 & 3.29 \\
\hline & $\mathrm{U}$ & 2.68 & 2.73 & 2.48 & 2.35 & 2.45 & 2.97 & 1.13 & 2.67 \\
\hline & $3 \mathrm{D}$ & 4.89 & 5.97 & 6.20 & 4.43 & 5.23 & 5.31 & 3.82 & 4.95 \\
\hline \multirow{4}{*}{ ORID } & E & 1.81 & 3.88 & 3.12 & 3.53 & 3.05 & 3.2 & 2.01 & 2.59 \\
\hline & $\mathrm{N}$ & 3.49 & 3.55 & 4.3 & 1.04 & 3.03 & 4.06 & 3.26 & 3.25 \\
\hline & $\mathrm{U}$ & 2.43 & 2.18 & 2.32 & 2.71 & 3.09 & 0.69 & 2.03 & 2.54 \\
\hline & $3 \mathrm{D}$ & 4.62 & 5.69 & 5.80 & 4.57 & 5.29 & 5.22 & 4.33 & 4.87 \\
\hline \multirow{4}{*}{ STJO } & E & 1.77 & 3.6 & 3.22 & 3.62 & 3.02 & 3.26 & 2.48 & 2.7 \\
\hline & $\mathrm{N}$ & 3.25 & 3.41 & 4.13 & 1.11 & 3.68 & 3.69 & 3.51 & 3.37 \\
\hline & $\mathrm{U}$ & 1.98 & 2.45 & 2.15 & 2.61 & 2.48 & 3.14 & 1.93 & 2.44 \\
\hline & $3 \mathrm{D}$ & 4.20 & 5.53 & 5.66 & 4.60 & 5.37 & 5.84 & 4.71 & 4.96 \\
\hline \multirow{4}{*}{ SALU } & E & 2.15 & 3.41 & 3.37 & 3.56 & 3.12 & 3.09 & 2.72 & 2.46 \\
\hline & $\mathrm{N}$ & 3.91 & 3.71 & 4.36 & 0.95 & 3.21 & 3.82 & 3.44 & 3.52 \\
\hline & $\mathrm{U}$ & 1.74 & 2.37 & 2.02 & 2.42 & 3.15 & 3.32 & 1.36 & 2.27 \\
\hline & $3 \mathrm{D}$ & 4.79 & 5.57 & 5.87 & 4.41 & 5.47 & 5.93 & 4.59 & 4.86 \\
\hline
\end{tabular}


Table 7. Cont.

\begin{tabular}{lccccccccc}
\hline \multirow{5}{*}{ CAS1 } & $\mathrm{E}$ & 1.66 & 3.25 & 3.12 & 3.47 & 3.06 & 3.15 & 2.25 & 2.32 \\
& $\mathrm{~N}$ & 3.66 & 3.83 & 4.17 & 1.32 & 4.2 & 4.36 & 3.33 & 3.61 \\
& $\mathrm{U}$ & 1.85 & 2.28 & 2.22 & 2.53 & 0.91 & 0.77 & 1.45 & 2.53 \\
& 3D & 4.42 & 5.52 & 5.66 & 4.49 & 5.28 & 5.43 & 4.27 & 4.98 \\
\hline \multirow{5}{*}{ CHOF } & $\mathrm{E}$ & 1.73 & 3.02 & 3.21 & 3.33 & 3.16 & 3.01 & 2.07 & 2.23 \\
& $\mathrm{~N}$ & 3.71 & 3.99 & 4.02 & 1.25 & 3.69 & 3.14 & 3.02 & 3.85 \\
& $\mathrm{U}$ & 1.92 & 2.02 & 2.05 & 2.81 & 1.83 & 3.18 & 1.55 & 2.55 \\
& 3D & 4.52 & 5.40 & 5.54 & 4.53 & 5.19 & 5.39 & 3.98 & 5.13 \\
\hline \multirow{5}{*}{ RIO2 } & $\mathrm{E}$ & 1.87 & 3.01 & 3.12 & 3.67 & 3.19 & 3.22 & 1.94 & 2.44 \\
& $\mathrm{~N}$ & 3.55 & 3.7 & 4.21 & 1.04 & 3.78 & 3.64 & 3.51 & 3.59 \\
& $\mathrm{U}$ & 1.68 & 1.93 & 2.13 & 2.36 & 1.91 & 3.02 & 1.64 & 2.47 \\
HARB & 3D & 4.35 & 5.15 & 5.66 & 4.49 & 5.30 & 5.72 & 4.33 & 4.99 \\
\hline \multirow{5}{*}{ Average } & $\mathrm{E}$ & 1.91 & 3.32 & 3.17 & 3.51 & 3.16 & 3.2 & 1.83 & 2.32 \\
& $\mathrm{~N}$ & 3.46 & 3.51 & 3.66 & 1.23 & 3.45 & 3.34 & 3.57 & 3.45 \\
& $\mathrm{U}$ & 1.82 & 1.73 & 2.00 & 2.87 & 2.01 & 2.95 & 1.77 & 2.29 \\
& 3D & 4.32 & 5.17 & 5.26 & 4.70 & 5.09 & 5.50 & 4.36 & 4.79 \\
\hline
\end{tabular}

\subsection{Result of Real-Time PPP in Simulated Kinematic Mode}

In this section, the selected reference stations were tested for simulated kinematic mode. Since the processing strategy was designed as a kinematic mode, the positioning result with the data from a static station can be generally considered as the best performance the real kinematic mode can achieve. This is because the effect of cycle slip, multi-path, and the interruption of signals can be reduced as much as possible.

RTPosNavi_AOE receives the real-time raw data and the GNSS satellite orbit and clock products via the IGG-Ntrip software and carries out the PPP result. Taking CEDU station as an example, our experiment began at 00:00:00 (UTC) on 12 September 2017 and lasted for $20 \mathrm{~h}$. IGS has released the known coordinates of every station and we directly used them as the reference for validating the positioning accuracy. The time series of the differences between the PPP-estimated and IGS-released coordinates in the E, N, and U directions are shown in Figure 10, where the results based on the different real-time GNSS satellite orbit and clock products are individually illustrated by each sub-figure. The ranges of the vertical axis of each sub-figure were set as the same for convenience during comparison, and the horizontal axis was the hour from the experiment start time. With the exception of the real-time product from IGS03 and CLK80, the convergence time was usually less than $30 \mathrm{~min}$, and the positioning accuracy after finishing the convergence process was almost better than $15 \mathrm{~cm}$ in the $\mathrm{E}, \mathrm{N}$, and $\mathrm{U}$ directions.

Table 8 shows the average positioning accuracies of kinematic mode in the $\mathrm{E}, \mathrm{N}$, and $\mathrm{U}$ directions during all test periods (without the convergence time). The positioning result based on CNES CLK93 and ESA CLK51 had the best accuracy in the horizontal (about $4 \mathrm{~cm}$ ) and vertical (about $6 \mathrm{~cm}$ ) directions, respectively. Regarding 3D positioning accuracy, the CLK51 and CLK93 also had the best performance (about $6.90 \mathrm{~cm}$ ), followed by CLK10, CLK20, IGS03, CLK80, CLK70, and CAS01. It should be noted that the number of systems provided by different ACs was different, only the product from CNES CLK93 included all GPS, BDS, GLONASS, and Galileo systems. Nevertheless, we concluded that real-time PPP could achieve a positioning with an accuracy of about $10 \mathrm{~cm}$ provided one was able to obtain the real-time orbit and clock products from the current eight selected ACs. 

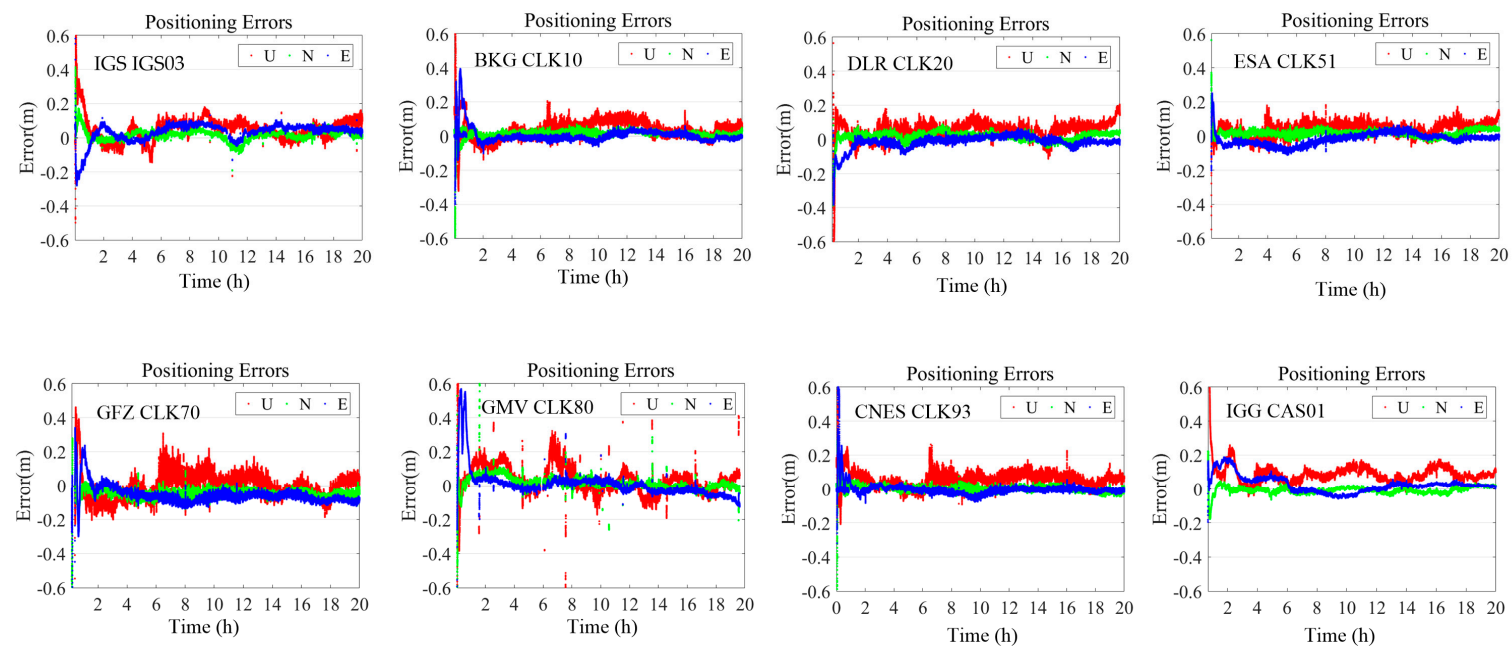

Figure 10. Time series of the differences between PPP-estimated (simulated kinematic mode) and IGS-released coordinates in E (East-West), N (North-South), $\mathrm{U}$ (Up-Down) directions at CEDU station. The results based on the real-time products from IGS03, CLK10, CLK20, CLK51, CLK70, CLK80, CLK93, and CAS01 are individually illustrated by each sub-figure.

Table 8. Simulated kinematic mode Positioning RMS of the PPP-estimated result using the orbit and clock products from different ACs.

\begin{tabular}{|c|c|c|c|c|c|c|c|c|c|}
\hline Stations & Direction $(\mathrm{cm})$ & $\begin{array}{c}\text { IGS } \\
\text { IGS03 }\end{array}$ & $\begin{array}{c}\text { BKG } \\
\text { CLK10 }\end{array}$ & $\begin{array}{c}\text { DLR } \\
\text { CLK20 }\end{array}$ & $\begin{array}{c}\text { ESA } \\
\text { CLK51 }\end{array}$ & $\begin{array}{c}\text { GFZ } \\
\text { CLK70 }\end{array}$ & $\begin{array}{c}\text { GMV } \\
\text { CLK80 }\end{array}$ & $\begin{array}{l}\text { CNES } \\
\text { CLK93 }\end{array}$ & $\begin{array}{c}\text { CAS } \\
\text { CAS01 }\end{array}$ \\
\hline \multirow{4}{*}{ CEDU } & $\mathrm{E}$ & 3.36 & 2.74 & 2.24 & 3.78 & 6.02 & 4.89 & 1.75 & 5.03 \\
\hline & $\mathrm{N}$ & 3.86 & 2.51 & 1.89 & 1.96 & 3.76 & 2.60 & 1.67 & 2.57 \\
\hline & $\mathrm{U}$ & 5.95 & 6.68 & 7.00 & 5.08 & 7.12 & 8.31 & 6.36 & 9.53 \\
\hline & $3 \mathrm{D}$ & 7.85 & 7.65 & 7.59 & 6.62 & 10.05 & 9.99 & 6.81 & 10.86 \\
\hline \multirow{4}{*}{ AZU1 } & $\mathrm{E}$ & 5.56 & 3.43 & 2.48 & 3.84 & 5.81 & 3.72 & 2.01 & 3.95 \\
\hline & $\mathrm{N}$ & 5.84 & 2.02 & 1.96 & 2.64 & 1.86 & 2.60 & 1.62 & 2.28 \\
\hline & $\mathrm{U}$ & 6.44 & 6.08 & 6.87 & 4.98 & 7.32 & 7.53 & 6.13 & 8.53 \\
\hline & $3 \mathrm{D}$ & 10.31 & 7.27 & 7.56 & 6.82 & 9.53 & 8.79 & 6.65 & 9.67 \\
\hline \multirow{4}{*}{ RVDI } & $\mathrm{E}$ & 4.83 & 3.39 & 2.88 & 2.56 & 4.99 & 4.19 & 4.45 & 4.81 \\
\hline & $\mathrm{N}$ & 4.71 & 2.34 & 1.86 & 1.78 & 3.24 & 2.58 & 2.03 & 3.22 \\
\hline & $\mathrm{U}$ & 6.02 & 6.71 & 6.54 & 5.99 & 6.99 & 7.76 & 5.33 & 8.56 \\
\hline & $3 \mathrm{D}$ & 9.04 & 7.87 & 7.38 & 6.75 & 9.18 & 9.19 & 7.23 & 10.33 \\
\hline \multirow{4}{*}{ ORID } & $\mathrm{E}$ & 5.17 & 2.68 & 2.49 & 2.81 & 5.12 & 4.13 & 3.03 & 4.11 \\
\hline & $\mathrm{N}$ & 4.06 & 1.93 & 2.04 & 1.90 & 3.99 & 2.54 & 2.52 & 2.48 \\
\hline & $\mathrm{U}$ & 5.98 & 5.99 & 7.13 & 5.88 & 7.41 & 8.49 & 4.89 & 9.67 \\
\hline & $3 \mathrm{D}$ & 8.88 & 6.84 & 7.82 & 6.79 & 9.85 & 9.78 & 6.28 & 10.79 \\
\hline \multirow{4}{*}{ STJO } & $\mathrm{E}$ & 4.41 & 3.16 & 2.37 & 3.78 & 3.84 & 5.66 & 1.82 & 4.81 \\
\hline & $\mathrm{N}$ & 4.51 & 1.70 & 1.98 & 2.07 & 2.64 & 3.79 & 1.55 & 2.85 \\
\hline & $\mathrm{U}$ & 5.79 & 7.33 & 6.96 & 6.01 & 8.73 & 7.42 & 6.43 & 9.34 \\
\hline & $3 \mathrm{D}$ & 8.56 & 8.16 & 7.34 & 7.40 & 9.89 & 10.07 & 6.86 & 10.89 \\
\hline \multirow{4}{*}{ SALU } & E & 5.47 & 2.22 & 3.73 & 2.75 & 4.91 & 4.32 & 3.48 & 5.16 \\
\hline & $\mathrm{N}$ & 4.06 & 1.85 & 2.86 & 1.88 & 3.67 & 2.40 & 2.33 & 2.63 \\
\hline & $\mathrm{U}$ & 6.07 & 6.78 & 6.44 & 5.63 & 7.41 & 8.61 & 5.33 & 8.98 \\
\hline & $3 \mathrm{D}$ & 9.12 & 7.37 & 7.97 & 6.54 & 9.62 & 9.92 & 6.78 & 10.68 \\
\hline
\end{tabular}


Table 8. Cont.

\begin{tabular}{cccccccccc}
\hline \multirow{5}{*}{ CAS1 } & $\mathrm{E}$ & 4.77 & 3.19 & 2.45 & 4.01 & 6.13 & 4.94 & 2.12 & 4.26 \\
& $\mathrm{~N}$ & 3.62 & 2.21 & 1.78 & 1.88 & 2.65 & 2.59 & 1.83 & 2.52 \\
& $\mathrm{U}$ & 5.11 & 6.93 & 6.89 & 5.68 & 8.03 & 7.81 & 6.16 & 9.83 \\
& 3D & 7.87 & 7.94 & 7.53 & 7.20 & 10.44 & 9.60 & 6.77 & 11.01 \\
\hline \multirow{5}{*}{ CHOF } & $\mathrm{E}$ & 5.02 & 3.68 & 4.57 & 3.13 & 5.24 & 3.99 & 2.86 & 3.91 \\
& $\mathrm{~N}$ & 5.94 & 1.74 & 2.05 & 1.99 & 2.84 & 2.06 & 1.71 & 2.00 \\
& $\mathrm{U}$ & 6.74 & 6.89 & 5.72 & 5.98 & 8.01 & 8.57 & 6.73 & 10.06 \\
& 3D & 10.29 & 8.00 & 7.60 & 7.04 & 9.98 & 9.67 & 7.51 & 11.71 \\
\hline \multirow{5}{*}{ RIO2 } & $\mathrm{E}$ & 4.33 & 2.89 & 2.92 & 3.23 & 5.53 & 4.73 & 2.11 & 4.74 \\
& $\mathrm{~N}$ & 5.15 & 2.10 & 1.76 & 2.34 & 2.35 & 1.83 & 1.97 & 1.74 \\
& $\mathrm{U}$ & 6.54 & 6.76 & 7.09 & 5.46 & 7.24 & 7.94 & 6.88 & 8.67 \\
& $3 \mathrm{D}$ & 9.38 & 7.64 & 7.87 & 6.76 & 9.41 & 9.42 & 7.46 & 10.03 \\
\hline \multirow{5}{*}{ HARB } & $\mathrm{E}$ & 4.68 & 3.14 & 2.48 & 4.01 & 5.88 & 5.01 & 2.12 & 5.65 \\
& $\mathrm{~N}$ & 5.51 & 2.24 & 1.96 & 1.91 & 3.69 & 3.08 & 2.01 & 2.25 \\
& $\mathrm{U}$ & 6.02 & 6.40 & 6.79 & 6.08 & 7.37 & 7.76 & 6.09 & 8.84 \\
\multirow{5}{*}{ Average } & 3D & 9.41 & 7.47 & 7.49 & 7.52 & 10.12 & 9.99 & 6.75 & 10.72 \\
& $\mathrm{E}$ & 4.76 & 3.05 & 2.86 & 3.39 & 5.35 & 4.56 & 2.58 & 4.64 \\
& $\mathrm{~N}$ & 4.73 & 2.06 & 2.02 & 2.04 & 3.07 & 2.61 & 1.92 & 2.45 \\
& $\mathrm{U}$ & 6.07 & 6.65 & 6.74 & 5.67 & 7.56 & 8.02 & 6.03 & 8.84 \\
\hline
\end{tabular}

\section{Positioning Result of Real-Time Kinematic PPP in Urban Experiment}

In this section, we conducted a real kinematic test in the cities of Beijing, Tianjin, and Shijiazhuang in China for a better understanding of the impact of real-time orbit and clock products from different ACs on the accuracy of PPP. Based on the analysis result, we found that the performance of the real-time GPS and BDS orbit (CLK93) from CNES was the best one among the eight selected ACs and is the only center that can simultaneously broadcast GPS, BDS, GLONASS, and Galileo products. Moreover, the BDS orbit and clock product began broadcasting by CAS01 from October 2017 in the test phase. Thus, the real-time satellite orbit and clock product from CLK93 and CAS01 were only selected in this experiment, as the test result could indicate the different performances of the products from those two ACs.

The terminal used for this real-time kinematic PPP experiment was assembled by integrating a NovAtel GNSS receiver board 618 and an Advanced RISC Machines (ARM) for the PPP calculation; a $4 \mathrm{G}$ mobile communication module was used for receiving the real-time orbit and clock product from the servers. The NovAtel GNSS receiver board can track the GPS, BDS, GLONASS, and Galileo signals and output the raw observations with an interval of $1 \mathrm{~s}$. The PPP software RTPosNavi_AOE was installed on the corresponding ARM and the positioning result was sent to our servers for showing on a precise map. The terminal and precise map are given in Figure 11. Moreover, we used two terminals in our test, one was only for the GPS mode and the other for the GPS+BDS mode. Two copies of RTPosNavi_AOE were run on the ARM to use the real-time products from CLK93 and CAS01, respectively. To obtain the real coordinates for the positioning accuracy validation, the IGS final orbit and clock product were introduced for PPP resolution in a post-processing mode. 

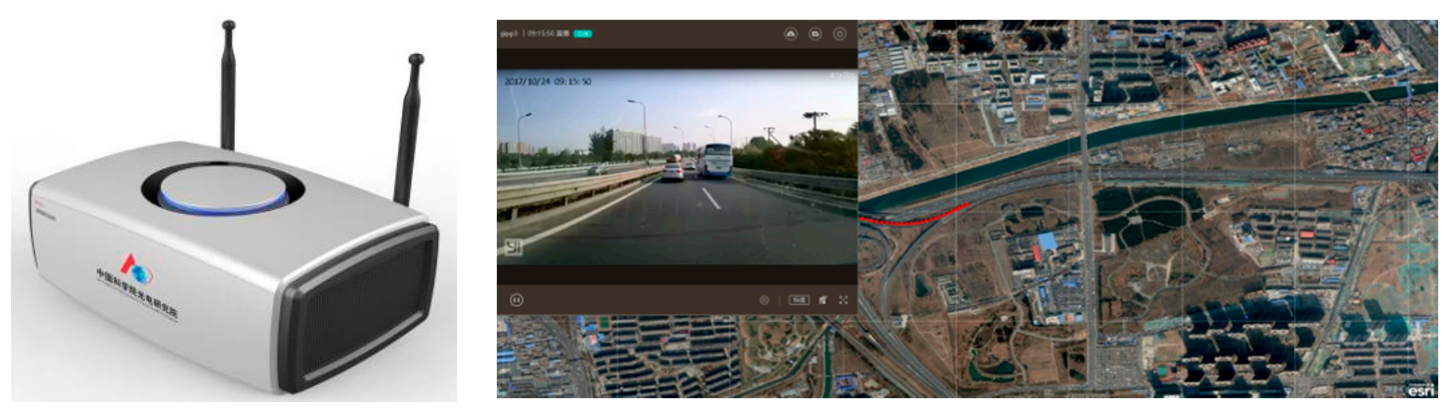

Figure 11. The positioning terminal (left) and the precise map (right) used for the real-time kinematic PPP test.

The test was carried out in Beijing, Tianjin, and Shijiazhuang individually during the periods of 10:00:00 to 12:30:00 (UTC) on 22 October 2017, 15:40:00 to 17:00:00 (UTC) on 24 October 2017 and 13:00:00 to 14:40:00 (UTC) on 26 October 2017. The maximum speed of the experimental vehicle was about $80 \mathrm{~km} / \mathrm{h}$. The experiment routes in these three cities included the urban, expressway, and flyover environment and are individually displayed in Figure 12. The distances of these three routes were about $23.5,34.2$, and $26.1 \mathrm{~km}$, respectively.
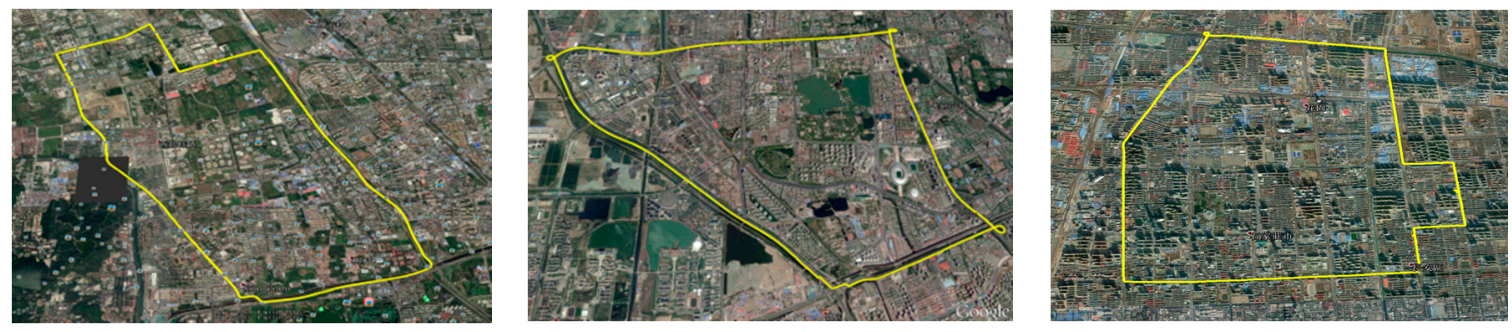

Figure 12. The road selected for our experiment in Beijing (left), Tianjin (middle), and Shijiazhuang (right).

Figure 13 shows the time series of the differences between the real-time PPP-estimated and post PPP at the different cities in the E (East-West), N (North-South), and U (Up-Down) directions. The results were based on the real-time products from CLK93 where the convergence time was usually also less than $30 \mathrm{~min}$, and the positioning accuracy after finishing the convergence process was almost better than $0.5 \mathrm{~m}$ in all directions. The accuracy of the real-time kinematic PPP result based on the products from CLK93 and CAS01 in GPS and GPS + BDS modes are illustrated in Table 9, where the result during the convergence period is not removed. It was found that the positioning accuracy of the simulated kinematic PPP decreased significantly with respect to the static result in Section 5.2 regardless of which product was used. The average accuracies of the real-time kinematic PPP based on the CLK93 product were about $0.45-0.65 \mathrm{~m}$ and $0.75-1.5 \mathrm{~m}$ in the horizontal and vertical directions, respectively, whereas they were about $0.50-0.65 \mathrm{~m}$ and $0.70-1.20 \mathrm{~m}$ for CAS01, except for the horizontal accuracy in Tianjin. The reason why the positioning result based on CAS01 in Tianjin was much worse than that in other cities needs to be further investigated. 

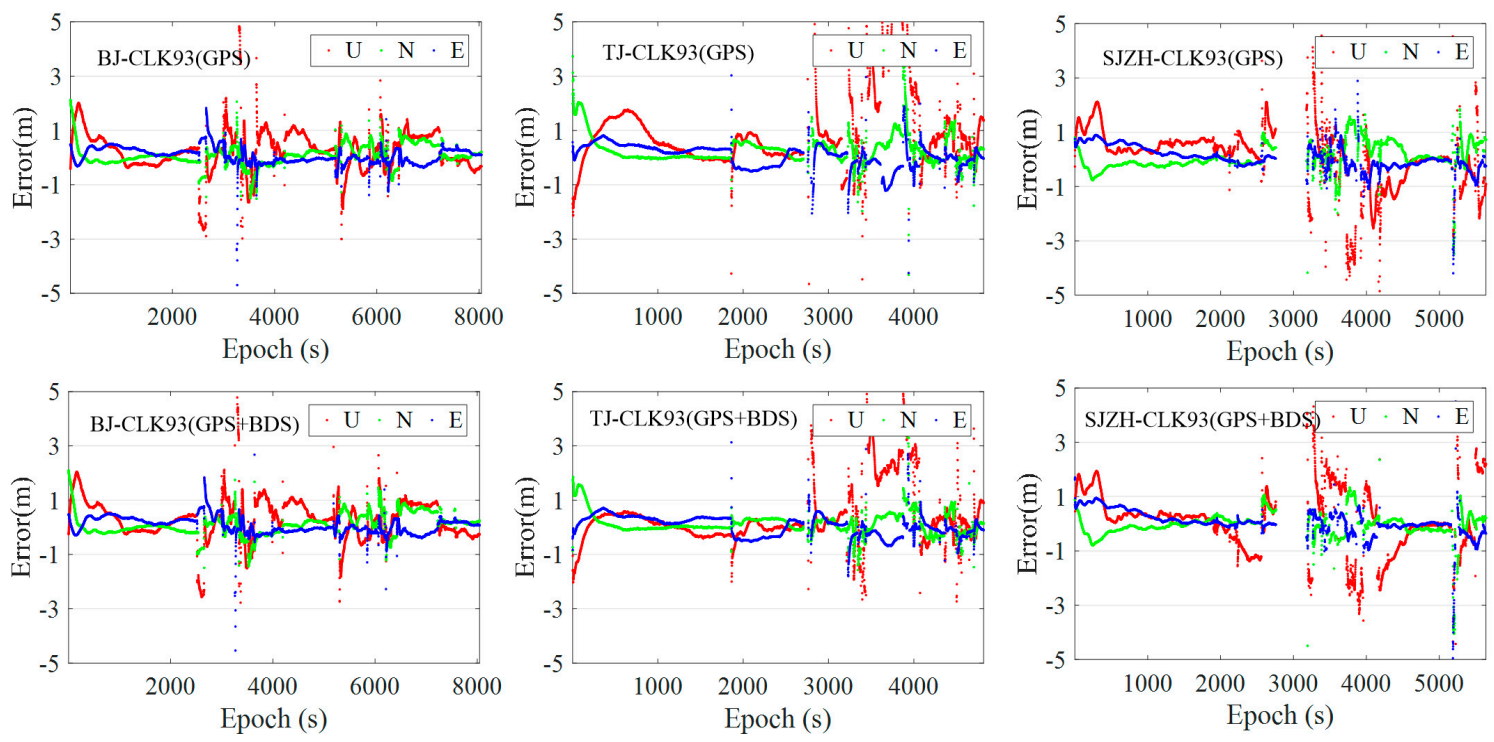

Figure 13. Time series of the differences between real-time PPP-estimated and post PPP at Beijing (left), Tianjin (middle), and Shijiazhuang (right) in the E, N, and U directions. The results of GPS (top) and GPS + BDS (bottom) based on the real-time products from CLK93 are only shown here.

Moreover, comparing the GPS result with that of GPS + BDS, the positioning accuracies were all slightly improved in the horizontal and vertical directions regardless of which product was used. The average accuracies in the Beijing, Tianjin, and Shijiazhuang areas are also given in Table 9. We found that the real-time kinematic PPP could achieve the positioning with an accuracy of better than 0.6 and $1.0 \mathrm{~m}$ in the horizontal and vertical directions based on the real-time orbit and clock product from CLK93, while they were 0.95 and $1.0 \mathrm{~m}$ for CAS01. The product from CAS needs to be improved further.

Table 9. The accuracies of real-time kinematic PPP using the CLK93 and CAS01 in GPS and GPS + BDS modes.

\begin{tabular}{|c|c|c|c|c|c|}
\hline \multirow{2}{*}{ City } & \multirow{2}{*}{ Product } & \multirow{2}{*}{ System } & \multicolumn{2}{|c|}{ Accuracy (m) } & \multirow{2}{*}{ Available Epochs } \\
\hline & & & Horizontal & Vertical & \\
\hline \multirow{4}{*}{ Beijing } & \multirow{2}{*}{ CLK93 } & GPS & 0.47 & 0.78 & 8005 \\
\hline & & GPS + BDS & 0.46 & 0.73 & 8023 \\
\hline & \multirow{2}{*}{ CAS01 } & GPS & 0.60 & 0.77 & 8005 \\
\hline & & GPS + BDS & 0.56 & 0.74 & 8023 \\
\hline \multirow{4}{*}{ Tianjin } & \multirow{2}{*}{ CLK93 } & GPS & 0.63 & 1.06 & 4615 \\
\hline & & GPS + BDS & 0.51 & 0.50 & 4758 \\
\hline & \multirow{2}{*}{ CAS01 } & GPS & 1.38 & 0.92 & 4615 \\
\hline & & GPS + BDS & 1.29 & 0.89 & 4758 \\
\hline \multirow{4}{*}{ Shijiazhuang } & \multirow{2}{*}{ CLK93 } & GPS & 0.62 & 1.14 & 5500 \\
\hline & & GPS + BDS & 0.53 & 0.83 & 5591 \\
\hline & \multirow{2}{*}{ CAS01 } & GPS & 0.60 & 1.16 & 5500 \\
\hline & & GPS + BDS & 0.53 & 1.08 & 5591 \\
\hline \multirow{4}{*}{ Average } & \multirow{2}{*}{ CLK93 } & GPS & 0.58 & 1.01 & 18,120 \\
\hline & & GPS + BDS & 0.50 & 0.70 & 18,372 \\
\hline & \multirow{2}{*}{ CAS01 } & GPS & 0.94 & 0.96 & 18,120 \\
\hline & & GPS + BDS & 0.87 & 0.91 & 18,372 \\
\hline
\end{tabular}




\section{Conclusions}

The SSR product including the real-time orbit and clock corrections is an essential and indispensable product for the GPS/BDS/GLONASS/Galileo PPP user achieving precise point positioning in real-time mode. In this study, a brief introduction of the methods to use real-time products for correcting satellite orbit and clock errors was summarized and the accuracy of real-time orbit and clock products from eight selected ACs were validated by using IGS, ESA, and GBM precise products as references. Further insights into PPP performance were provided by using static data to simulate kinematic positioning and real-time kinematic tests. The main conclusions are presented as follows:

1. A comparison of real-time precise products developed by eight selected ACs, i.e., BKG, DLR, ESA, GFZ, GMV, CNES, CAS, and IGS, with respect to the final precise products, showed that the RMS of differences for GPS between real-time orbit and IGS final orbit was better than $8 \mathrm{~cm}$, whereas the STD of GPS clock differences was better than $0.3 \mathrm{~ns}$. The RMS of GLONASS orbit differences between the real-time product and ESA final product was less than $10 \mathrm{~cm}$, and clock STD was better than $0.6 \mathrm{~ns}$, except for CAS01. The 1DRMS of orbit differences for BDS and Galileo in the CLK93 product were 14.54 and $4.42 \mathrm{~cm}$, respectively, in contrast to 0.32 and $0.18 \mathrm{~ns}$ for clock STD.

2. Static mode and simulated kinematic mode PPP results from 10 stations in the IGS/MGEX network indicated that the PPP results using real-time products developed by BKG, DLR, ESA, GFA, GMV, CNES, and CAS needed nearly the same convergence time (about 20-30 $\mathrm{min}$ ) to reach about $10 \mathrm{~cm}$ and $15 \mathrm{~cm}$ level accuracy as using IGS final precise ephemeris and clock products.

3. CNES and CAS products were selected for the real-time kinematic PPP tests carried out in Beijing, Tianjin, and Shijiazhuang, China. Results indicated that CLK93 products showed a higher accuracy than CAS01 in real-time kinematic PPP, horizontally and vertically, when being tested under the same conditions. Moreover, when using the same product for real-time PPP solution, the GPS + BDS dual system showed higher accuracy than the GPS single system.

4. The real-time SSR product from the eight selected ACs was advantageous to aid the real-time PPP user achieving positioning with sub-meter level accuracy (including the result during the convergence or re-convergence period) in the horizontal direction and could be used for lane identification in the near future.

It must be pointed out that the tests conducted in this paper were only based on one-week data from real-time products. Data from a longer timeframe will be used for the follow-up research, where real-time data from reference stations in different locations and different periods will be collected for systematic assessment and analysis of real-time product performance.

Acknowledgments: Partially funded by the National Natural Science Foundation of China (41674043, 41704038, 41730109), the National Key Research Program of China "Collaborative Precision Positioning Project" (No. 2016YFB050190), Beijing Nova program (xx2017042), Beijing Natural Science Foundation (8184092) and Beijing youth talent support program (2017000021223ZK13). The third author acknowledges the financial support from the China Scholarship Council. Thanks also to the IGG-Ntrip software provided by the Institute of Geodesy and Geophysics, Chinese Academy of Sciences, the original observations provided by IGS, and the multi-system SSR products provided by the analysis centers such as BKG, GMV, and CNES.

Author Contributions: Zishen Li and Liang Wang conceived and designed the experiments; Zhiyu Wang performed the experiments, analyzed the data, and wrote the paper; Liang Wang also helped to analyze the data; Zishen Li, Liang Wang, Xiaoming Wang, and Hong Yuan helped to improve the manuscript.

Conflicts of Interest: The authors declare no conflict of interest.

\section{References}

1. Abdi, N.; Ardalan, A.A.; Karimi, R.; Rezvani, M.H. Performance assessment of multi-gnss real-time ppp over iran. Adv. Space Res. 2017, 59, 2870-2879. [CrossRef] 
2. Barsever, Y.; Muellerschoen, R. NASA's global differential gps system. In Proceedings of the EGS-AGU-EUG Joint Assembly, Nice, France, 6-11 April 2003.

3. Ge, M.; Chen, J.; Douša, J.; Gendt, G.; Wickert, J. A computationally efficient approach for estimating high-rate satellite clock corrections in realtime. GPS Solut. 2012, 16, 9-17. [CrossRef]

4. Hauschild, A.; Montenbruck, O. Kalman-filter-based gps clock estimation for near real-time positioning. GPS Solut. 2009, 13, 173-182. [CrossRef]

5. Huang, G.; Zhang, Q.; Li, H.; Fu, W. Quality variation of gps satellite clocks on-orbit using igs clock products. Adv. Space Res. 2013, 51, 978-987. [CrossRef]

6. Yu, X.; Gao, J. Kinematic precise point positioning using multi-constellation global navigation satellite system (gnss) observations. Int. J. Geo-Inf. 2017, 6, 6. [CrossRef]

7. Asari, K.; Suzuki, T.; Kubo, N.; Shima, M.; Saito, M. Ssr ppp for asia-pacific services. In Proceedings of the 27th International Technical Meeting of the Satellite Division of the Institute of Navigation, ION GNSS 2014, Tampa, FL, USA, 8-12 September 2014.

8. Bar-Sever, Y.; Bell, B.; Dorsey, A.; Srinivasan, J. Space Applications of the Nasa Global Differential GPS System; Jpl Technical Reports; Institute of Navigation: Portland, OR, USA, 2003.

9. Mervart, L.; Weber, G. Real-time combination of gnss orbit and clock correction streams using a kalman filter approach. In Proceedings of the International Technical Meeting of the Satellite Division of the Institute of Navigation (ION GNSS 2011), Portland, OR, USA, 20-23 September 2011; pp. 707-711.

10. Dixon, K. Starfire ${ }^{\mathrm{TM}}$ : A global sbas for sub-decimeter precise point positioning. In Proceedings of the International Technical Meeting of the Satellite Division of the Institute of Navigation (ION GNSS 2006), Fort Worth, TX, USA, 26-29 September 2006; pp. 2286-2296.

11. Kouba, J. A Guide to Using International Gnss Service (Igs) Products; IGS Central Bureau: Pasadena, CA, USA, 2009.

12. Melgard, T.; Vigen, E.; Jong, K.D.; Lapucha, D.; Visser, H.; Oerpen, O. G2-the first real-time gps and glonass precise orbit and clock service. In Proceedings of the International Technical Meeting of the Satellite Division of the Institute of Navigation (ION GNSS 2009), Savannah, GA, USA, 22-25 September 2009; pp. 1885-1891.

13. IGS International GNSS Service. Available online: http:/ / www.igs.org/products (accessed on 7 February 2018).

14. Caissy, M.; Agrotis, L.; Weber, G.; Hernandez-Pajares, M.; Hugentobler, U. Coming Soon: The International Gnss Real-Time Service. GPS World 2012, 23, 52-58.

15. Chen, L.; Zhao, Q.; Hu, Z.; Jiang, X.; Geng, C.; Ge, M.; Shi, C. Gnss global real-time augmentation positioning: Real-time precise satellite clock estimation, prototype system construction and performance analysis. Adv. Space Res. 2018, 61, 367-384. [CrossRef]

16. Colombo, O. Real-time, wide-area, precise kinematic positioning using data from internet ntrip streams. In Proceedings of the 21st International Technical Meeting of the Satellite Division of The Institute of Navigation (ION GNSS 2008), Network Rtk Session, Savannah, GA, USA, 16-19 September 2008.

17. Li, Z.; Zhang, J.; Li, T.; He, X.; Wu, M. Analysis of static and dynamic real-time precise point positioning and precision based on ssr correction. In Proceedings of the IEEE International Conference on Information and Automation, Macau, China, 18-20 July 2017; pp. 2022-2027.

18. Liu, Z.Q.; Wang, J.X. Realization and analysis of real-time precise point positioning based on ssr broadcast ephemeris corrections. Sci. Surv. Mapp. 2014, 39, 15-19.

19. Wang, L.; Li, Z.; Ge, M.; Neitzel, F.; Wang, Z.; Yuan, H. Validation and assessment of multi-gnss real-time precise point positioning in simulated kinematic mode using igs real-time service. Remote Sens. 2018, 10, 337. [CrossRef]

20. Weber, G.; Mervart, L.; Lukes, Z.; Rocken, C.; Dousa, J. Real-time clock and orbit corrections for improved point positioning via Ntrip. In Proceedings of the ION GNSS 20th International Technical Meeting of the Satellite Division, Fort Worth, TX, USA, 25-28 September 2007; pp. 1992-1998.

21. Zhang, B. Three methods to retrieve slant total electron content measurements from ground-based gps receivers and performance assessment. Radio Sci. 2016, 51, 972-988. [CrossRef]

22. Jiao, W. International GNSS Monitoring and Assessment System (iGMAS) and latest progress. In Proceedings of the China Satellite Navigation Conference (CSNC), Nanjing, China, 21-23 May 2014.

23. International GNSS Monitoring \& Assessment System. Available online: http://www.igmas.org (accessed on 7 February 2018). 
24. Zumberge, J.F.; Heflin, M.B.; Jefferson, D.C.; Watkins, M.M.; Webb, F.H. Precise point positioning for the efficient and robust analysis of gps data from large networks. J. Geophys. Res. Solid Earth 1997, 102, 5005-5017. [CrossRef]

25. Gebhard, H.; Weber, G. NTRIP: Networked transport of rtcm via internet protocol—Internet radio technology for real-time gnss purposes. In Proceedings of the AGU Fall Meeting, San Francisco, CA, USA, 8-12 December 2003.

26. Collins, P.; Gao, Y.; Lahaye, F.; Héroux, P.; Macleod, K.; Chen, K. Accessing and processing real-time gps corrections for precise point positioning ... some user considerations. In Proceedings of the International Technical Meeting of the Satellite Division of the Institute of Navigation (ION GNSS 2005), Long Beach, CA, USA, 13-16 September 2005; pp. 1483-1491.

27. Pérez, J.; Agrotis, L.; Fernández, J.; Garcia, C.; Dow, J. Esa/esoc real time data processing. In Proceedings of the IGS workshop 2006, Darmstadt, Germany, 8-11 May 2006.

28. Zhang, X.; Li, X.; Guo, F. Satellite clock estimation at $1 \mathrm{hz}$ for realtime kinematic ppp applications. GPS Solut. 2011, 15, 315-324. [CrossRef]

29. El-Mowafy, A.; Deo, M.; Kubo, N. Maintaining real-time precise point positioning during outages of orbit and clock corrections. GPS Solut. 2017, 21, 937-947. [CrossRef]

30. Elsobeiey, M.; Al-Harbi, S. Performance of real-time precise point positioning using igs real-time service. GPS Solut. 2016, 20, 565-571. [CrossRef]

31. Hadas, T.; Bosy, J. Igs Rts Precise Orbits and Clocks Verification and Quality Degradation over Time; Springer: New York, NY, USA, 2015; pp. 93-105.

32. Ge, M.; Zhang, H.; Jia, X.; Song, S.; Wickert, J. What is achievable with the current compass constellation? GPS World 2012, 1, 29-34.

33. Martín, A.; Hadas, T.; Dimas, A.; Anquela, A.B.; Berné, J.L. Influence of real-time products latency on kinematic ppp results. In Proceedings of the ESA 5th International Colloquium on Scientific and Fundamental Aspects of the Galileo Program, Braunschweig, Germany, 27-29 October 2015.

34. Chen, Y.; Yuan, Y.; Ding, W.; Zhang, B.; Liu, T. Glonass pseudorange inter-channel biases considerations when jointly estimating gps and glonass clock offset. GPS Solut. 2017, 21, 1525-1533. [CrossRef]

35. Song, W.; Yi, W.; Lou, Y.; Shi, C.; Yao, Y.; Liu, Y.; Mao, Y.; Xiang, Y. Impact of glonass pseudorange inter-channel biases on satellite clock corrections. GPS Solut. 2014, 18, 323-333. [CrossRef] 